\title{
PPAR $\gamma$ in the endothelium regulates metabolic responses to high-fat diet in mice
}

\author{
Takeshi Kanda, ${ }^{1}$ Jonathan D. Brown, ${ }^{1}$ Gabriela Orasanu, ${ }^{1}$ Silke Vogel, ${ }^{2}$ Frank J. Gonzalez, ${ }^{3}$ \\ Juliano Sartoretto, ${ }^{1}$ Thomas Michel, ${ }^{1}$ and Jorge Plutzky ${ }^{1}$
}

\begin{abstract}
1Division of Cardiovascular Medicine, Department of Medicine, Brigham and Women's Hospital, Harvard Medical School, Boston, Massachusetts, USA. 2Department of Medicine, Columbia University College of Physicians and Surgeons, New York, New York, USA. ${ }^{3}$ Laboratory of Metabolism, Nucleic Acids Section, National Cancer Institute, NIH, Bethesda, Maryland, USA.
\end{abstract}

\begin{abstract}
Although endothelial dysfunction, defined as abnormal vasoreactivity, is a common early finding in individuals with type 2 diabetes, the endothelium has not been known to regulate metabolism. As PPAR $\gamma$, a transcriptional regulator of energy balance, is expressed in endothelial cells, we set out to investigate the role of endothelial cell PPAR $\gamma$ in metabolism using mice that lack PPAR $\gamma$ in the endothelium and BM $(\gamma E C / B M-K O)$. When $\gamma$ EC/BM-KO mice were fed a high-fat diet, they had decreased adiposity and increased insulin sensitivity compared with control mice, despite increased serum FFA and triglyceride (TG) levels. After fasting or olive oil gavage, $\gamma$ EC/BM-KO mice exhibited significant dyslipidemia and failed to respond to the FFA and TG lowering effects of the PPAR $\gamma$ agonist rosiglitazone. BM transplantation studies, which reconstituted hematopoietic $\operatorname{PPAR} \gamma$, established that these metabolic phenotypes were due to endothelial PPAR $\gamma$ deficiency. We further found that the impairment in TG-rich lipoprotein metabolism in $\gamma \mathrm{EC} / \mathrm{BM}-\mathrm{KO}$ mice was associated with fatty acid-mediated lipoprotein lipase inhibition and changes in a PPAR $\gamma$-regulated endothelial cell transcriptional program. Despite their metabolic improvements, high-fat diet-fed $\gamma \mathrm{EC} / \mathrm{BM}-\mathrm{KO}$ mice had impaired vasoreactivity. Taken together, these data suggest that PPAR $\gamma$ in the endothelium integrates metabolic and vascular responses and may contribute to the effects of PPAR $\gamma$ agonists, thus expanding what endothelial function and dysfunction may entail.
\end{abstract}

\section{Introduction}

The endothelium is now recognized as a biologically active dynamic organ involved in both physiologic and pathologic processes. For example, by virtue of their location, ECs facilitate metabolic exchange between the circulation and tissues (1). In obesity and its associated conditions of insulin resistance and diabetes, endothelial dysfunction is a common feature that may even precede the onset of frank diabetes $(2,3)$. In this context, endothelial dysfunction has been previously understood primarily in the context of abnormal vasomotor function. Specific mechanisms through which the endothelium itself may directly modulate obesity, lipid metabolism, or insulin sensitivity, have remained largely obscure.

The nuclear receptor PPAR $\gamma$ is a ligand-activated transcription factor involved in the control of energy balance. In addition to its role in adipocyte biology and adipogenesis $(4,5), \operatorname{PPAR} \gamma$ is also important in lipid metabolism, regulating genes that take part in the release, transport, and storage of fatty acids (FAs), including lipoprotein lipase (LPL) and the FA transporter CD36 (reviewed in ref. 6). PPAR $\gamma$-activating thiazolidinediones (TZDs), in use as antidiabetic agents, improve insulin sensitivity through their transcriptional effects. The effects of pharmacological PPAR $\gamma$ activation have been attributed, at least in part, to decreased FFA levels and increased lipid storage in adipose tissue, in which it is most highly expressed, thus reducing lipotoxicity in muscle and liver.

Conflict of interest: The authors have declared that no conflict of interest exists. Nonstandard abbreviations used: $a P 2$, adipocyte protein 2; BMT, BM transplantation/BM-transplanted; CM, chylomicron; CRBP-III, cellular retinol-binding protein III; FA, fatty acid; GPIHBP1, glycosylphosphatidylinositol-anchored HDLbinding protein 1; HL, hepatic lipase; LPL, lipoprotein lipase; TG, triglyceride; TZD, thiazolidinedione.

Citation for this article: J. Clin. Invest. 119:110-124 (2009). doi:10.1172/JCI36233.
We and others have demonstrated that PPAR $\gamma$ is also expressed in ECs, in which it regulates targets relevant to inflammation and atherosclerosis (refs. 7-9; reviewed in ref. 10). A specific role for endothelial PPAR $\gamma$ as a determinant of metabolic function has not been previously described.

Given the common and early presence of endothelial dysfunction in dyslipidemia, obesity, and diabetes and PPAR $\gamma$ as a regulator of energy balance expressed in the endothelium, we hypothesized that endothelial PPAR $\gamma$ might be involved in directing metabolic phenotype. To test this, we studied mice deficient in endothelial PPAR $\gamma$, using floxed PPAR $\gamma$ mice and a Cre transgene under control by the endothelial/hematopoietic specific Tie 2 promoter (11). We investigated these mice under conditions of standard chow and high-fat diet, both with and without treatment with the PPAR $\gamma$ agonist rosiglitazone as well as before and after BM transplantation (BMT) to reconstitute hematopoietic PPAR $\gamma$ expression and isolate endothelial PPAR $\gamma$-dependent responses. These studies reveal that mice specifically deficient in endothelial PPAR $\gamma$ manifest a distinct pattern of decreased adiposity, increased insulin action, worsened dyslipidemia, and impaired arterial vasodilation in response to high-fat diet challenges as compared with control mice. Moreover, these mice fail to exhibit known metabolic improvements in response to a PPAR $\gamma$ agonist. These data establish PPAR $\gamma$ in the endothelium as a previously unrecognized determinant of metabolic status and a potential contributor to metabolic abnormalities found in insulin resistance and diabetes.

\section{Results}

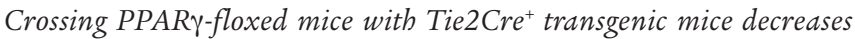
Pparg mRNA expression in EC and hematopoietic cells. The PPAR $\gamma-$ floxed mice crossed with $\mathrm{Tie}_{2} \mathrm{Cre}^{+}$mouse (referred to throughout 


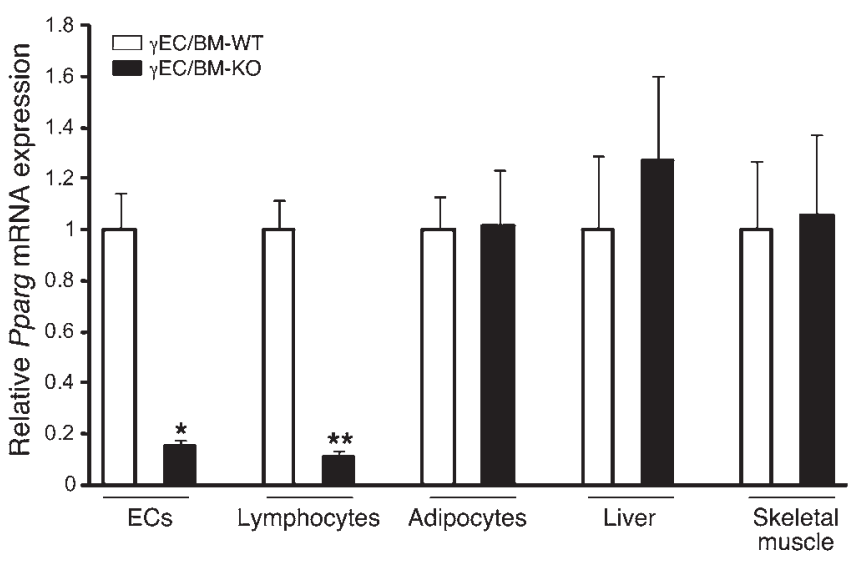

as $\gamma \mathrm{EC} / \mathrm{BM}-\mathrm{KO}$ ) has been previously described (11). The Tie2 promoter directs effective Cre expression, and hence PPAR $\gamma$ deletion, in ECs as well as BM-derived hematopoietic cells $(12,13)$. PPAR $\gamma$ deletion in $\gamma \mathrm{EC} / \mathrm{BM}-\mathrm{KO}$ mice was highly efficient in ECs isolated from the cardiac microvasculature and splenic lymphocytes (Figure 1) (14). Of note, this model is a "knockdown" but not complete "knockout" of PPAR $\gamma$ in these cellular settings. Pparg mRNA levels were unchanged in adipocytes, liver, and skeletal muscle (Figure 1). These results are consistent with Southern blot analysis of tissue DNA from these mice, which reveals complete recombination in the spleen and incomplete recombination elsewhere (11).

Tie2Cre-mediated PPAR $\gamma$ deletion decreases white adipose tissue mass and adipocyte size after high-fat diet feeding. To assess the role of Tie2Cre-mediated PPAR $\gamma$ deletion in the development of obesity and obesity-associated insulin resistance, we fed either standard low-fat (13.2\% calories derived from fat, Std) or high-fat (60\% calories derived from fat, HFD) diets to male $\gamma \mathrm{EC} / \mathrm{BM}-\mathrm{WT}$ and $\gamma \mathrm{EC} /$ $\mathrm{BM}-\mathrm{KO}$ mice. Body weight was comparable in both genotypes after either shorter (12 weeks; Figure 2A) or longer (27 weeks; Figure 2B) high-fat diet feeding. In spite of their similar body weights, inguinal and epididymal fat depots (normalized to body weights here and throughout) were significantly decreased in $\gamma \mathrm{EC} / \mathrm{BM}-\mathrm{KO}$ mice as compared with $\gamma \mathrm{EC} / \mathrm{BM}$-WT mice after 12 weeks of high-fat diet feeding (Figure 2C). The similar total body weights seen were likely due to significantly increased spleen and liver weights (but not kidney weight) in $\gamma \mathrm{EC} / \mathrm{BM}-\mathrm{KO}$ versus $\gamma \mathrm{EC} / \mathrm{BM}-\mathrm{WT}$ mice (Figure $2 \mathrm{C}$ ). Consistent with functional changes in adipose tissues, adipocyte size was decreased $25 \%$ in epididymal fat in high-fat diet-fed $\gamma \mathrm{EC} / \mathrm{BM}-\mathrm{KO}$ versus $\gamma \mathrm{EC} / \mathrm{BM}$-WT mice (Figure 2, D and E).

Tie2Cre-mediated PPAR $\gamma$ deletion improves glucose tolerance and insulin sensitivity in high-fat diet-fed obese mice. Given these differences in fat, we next measured fasting blood glucose and insulin concentrations in 4 groups of mice: standard chow-fed (lean) $\gamma \mathrm{EC} / \mathrm{BM}$ WT and $\gamma \mathrm{EC} / \mathrm{BM}-\mathrm{KO}$ and high-fat diet-fed (obese) $\gamma \mathrm{EC} / \mathrm{BM}-\mathrm{WT}$ and $\gamma \mathrm{EC} / \mathrm{BM}-\mathrm{KO}$ mice. Lean $\gamma \mathrm{EC} / \mathrm{BM}-\mathrm{WT}$ and $\gamma \mathrm{EC} / \mathrm{BM}-\mathrm{KO}$ mice had no differences in fasting blood glucose or insulin concentrations (Figure 3, A and B). In contrast, high-fat diet-fed obese $\gamma \mathrm{EC} / \mathrm{BM}-\mathrm{KO}$ mice had significantly lower concentrations of both fasting blood glucose and insulin as compared with obese $\gamma \mathrm{EC} /$ BM-WT mice (Figure 3, A and B). On glucose and insulin tolerance testing, obese $\gamma \mathrm{EC} / \mathrm{BM}-\mathrm{KO}$ mice were less hyperglycemic (Figure 3C) and more insulin sensitive (Figure 3D) as compared with obese $\gamma$ EC/BM-WT mice.

\section{Figure 1}

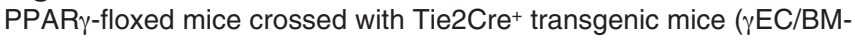
$\mathrm{KO}$ ) have decreased Pparg mRNA expression in endothelial and lymphocytes (hematopoietic cells) but not adipocytes, liver, or skeletal muscle as compared with PPAR $\gamma$-floxed mice crossed to Tie2Cremice ( $\gamma E C / B M-W T)$. Real-time quantitative PCR analysis of PPAR $\gamma$ expression in microvascular ECs, splenic lymphocytes, adipocytes, liver, and skeletal muscle isolated from Tie2Cre-expressing ( $\gamma \mathrm{EC} / \mathrm{BM}$ $\mathrm{KO}$ ) or nonexpressing ( $\gamma \mathrm{EC} / \mathrm{BM}-\mathrm{WT})$ mice $\left(n=3-5 /\right.$ group). ${ }^{\star} P<0.05$, ${ }^{* *} P<0.01 \gamma$ EC/BM-KO versus $\gamma$ EC/BM-WT mice.

Tie2Cre-mediated PPAR deletion alters levels of FA and triglyceride as well as muscle triglyceride accumulation in diet-induced obesity. We next explored what mechanisms might help explain the increased insulin sensitivity seen in high-fat diet-fed obese $\gamma \mathrm{EC} / \mathrm{BM}-\mathrm{KO}$ mice. Although decreased adiposity can be associated with changes in levels of adipocytokines (15), adiponectin, leptin, retinol binding protein 4, and resistin levels did not differ significantly between $\gamma \mathrm{EC} / \mathrm{BM}-\mathrm{KO}$ and $\gamma \mathrm{EC} / \mathrm{BM}-\mathrm{WT}$ mice (Figure 4A). Elevated circulating FFA and triglyceride (TG) levels are common in type 2 diabetes and obesity; insulin sensitivity is even more negatively correlated with TG levels in skeletal muscle than serum FFA levels $(16,17)$. Obese $\gamma \mathrm{EC} / \mathrm{BM}-\mathrm{KO}$ mice manifested increased fasting FFA and TG levels as compared with $\gamma \mathrm{EC} / \mathrm{BM}-\mathrm{WT}$ mice (Figure 4A). However, obese $\gamma \mathrm{EC} / \mathrm{BM}-\mathrm{KO}$ mice had less TG accumulation in skeletal muscle as compared with $\gamma \mathrm{EC} / \mathrm{BM}$-WT mice (Figure 4B), identifying this as a likely contributor to the increased insulin sensitivity found in Tie2Cre-mediated PPAR $\gamma$ deletion. Indeed, high-fat diet-fed $\gamma \mathrm{EC} / \mathrm{BM}-\mathrm{KO}$ mice demonstrated significantly increased insulin-induced AKT phosphorylation in skeletal muscle as compared with WT mice (Figure 4B). In contrast, total TG content was increased in the liver of $\gamma \mathrm{EC} / \mathrm{BM}-\mathrm{KO}$ mice, with concomitantly decreased insulin-induced AKT phosphorylation (Figure 4C). Similarly, levels of phosphorylated c-Jun-terminal kinase (JNK), another protein involved in insulin signaling pathways, were also decreased in skeletal muscle but increased in livers from $\gamma \mathrm{EC} /$ $\mathrm{BM}-\mathrm{KO}$ mice (data not shown). In contrast to expression in ECs, hepatic Pparg2 and Cd36 mRNA expression levels were significantly increased in $\gamma \mathrm{EC} / \mathrm{BM}-\mathrm{KO}$ mice (Figure 4C).

Endothelial PPAR $\gamma$ promotes adipose tissue growth. PPAR $\gamma$ activation increases adipose tissue mass, even when fed with a standard chow diet, stimulating adipocyte differentiation and TG accumulation in fat (18-20). To elucidate whether Tie2-mediated PPAR $\gamma$ deletion alters PPAR $\gamma$-mediated adipogenesis, $\gamma \mathrm{EC} / \mathrm{BM}-\mathrm{WT}$ and $\gamma \mathrm{EC} / \mathrm{BM}$ $\mathrm{KO}$ mice were treated with the PPAR $\gamma$ agonist rosiglitazone (15 $\mathrm{mg} / \mathrm{kg} / \mathrm{d}, 5$ weeks) when fed with a standard chow diet. As expected (18), rosiglitazone increased inguinal, epididymal, and brown adipose tissue weight (normalized to body weight) in $\gamma \mathrm{EC} / \mathrm{BM}-\mathrm{WT}$ mice; in contrast, rosiglitazone failed to increase epididymal fat weight in $\gamma \mathrm{EC} / \mathrm{BM}-\mathrm{KO}$ mice (Figure 5A). Even though differences in inguinal fat weight in the presence versus absence of Tie2-mediated PPAR $\gamma$ deletion did not reach statistical significance, inguinal adipose tissue in $\gamma \mathrm{EC} / \mathrm{BM}-\mathrm{KO}$ mice either at baseline or after rosiglitazone treatment contained significantly smaller adipocytes, 
A

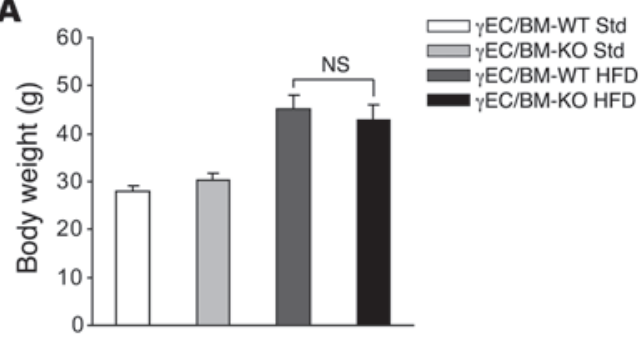

B

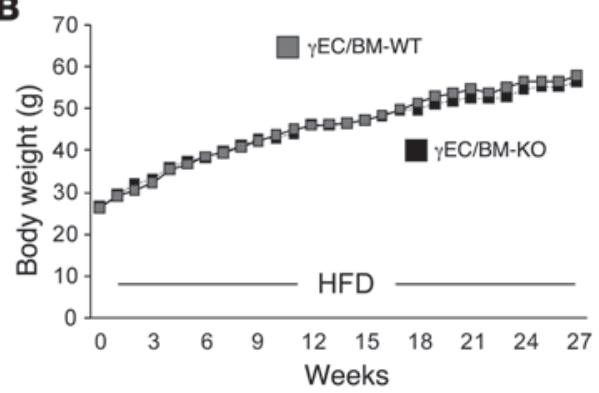

D
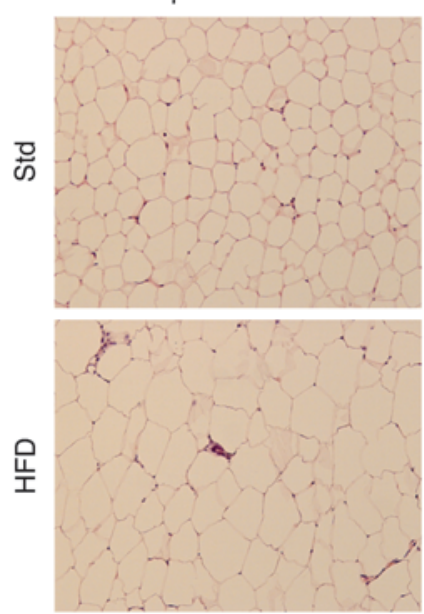

C
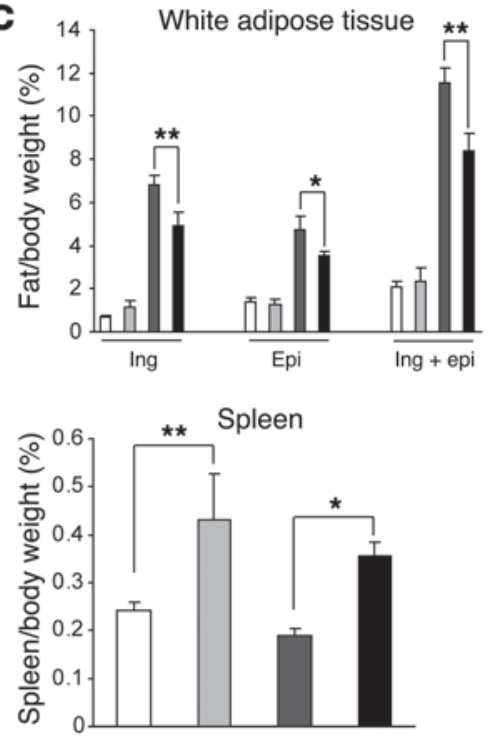

Liver

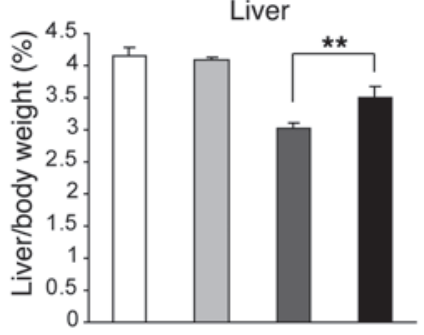

Kidney

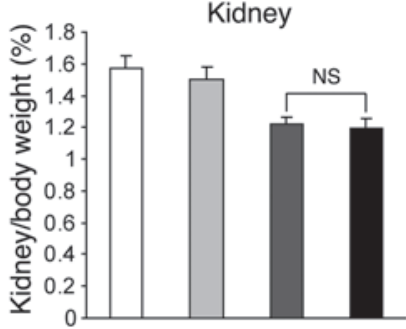

E

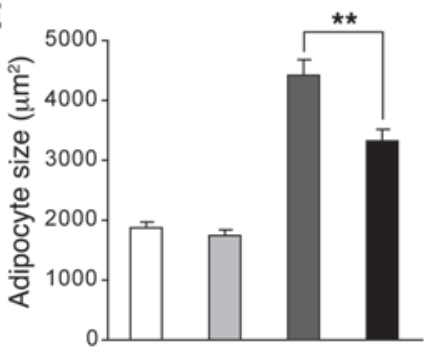

Figure 2

Tie2Cre-mediated PPAR $\gamma$ deletion decreases white adipose tissue mass and adipocyte size after high-fat diet. (A) Body weights of mice either with $(\gamma \mathrm{EC} / \mathrm{BM}-\mathrm{KO})$ or without $(\gamma \mathrm{EC} / \mathrm{BM}-\mathrm{WT})$ Tie2-mediated PPAR $\gamma$ deletion after standard chow or high-fat diet (12 weeks, here and throughout except as noted; $n=6$ ). (B) Weight gain over time of $\gamma \mathrm{EC} / \mathrm{BM}-\mathrm{WT}$ (gray squares) and $\gamma \mathrm{EC} / \mathrm{BM}-\mathrm{KO}$ (black squares) mice on high-fat diet ( $n=7-9$ /group). SEM $<8 \%$ for all measurements. (C) Tissue weight/total body weight of inguinal (ing), epididymal (epi), inguinal plus epididymal fat, liver, spleen, and kidney after standard chow or high-fat diet (12 weeks; $n=6)$. (D) Histology of epididymal adipose tissue from $\gamma E C / B M-K O$ and $\gamma E C / B M-W T$ mice on standard chow or high-fat diet as above. Scale bar: $200 \mu \mathrm{m}$. (E) Mean adipocyte size in $\gamma E C / B M-W T$ versus $\gamma E C / B M-$ KO mice $\left(n=5 /\right.$ group). ${ }^{\star} P<0.05,{ }^{\star \star} P<0.01$ versus $\gamma E C / B M-W T$ mice under the same diet.

as evident on H\&E staining and size analysis (Figure 5, B and C). These results indicate that PPAR $\gamma$ deletion via Tie2Cre expression in ECs and BM cells alters adipocyte hypertrophy and adipose tissue expansion in response to a PPAR $\gamma$ agonist in vivo.

To determine whether these defects in adipocyte responses and adipogenesis resulted specifically from endothelial PPAR $\gamma$, reconstitution of hematopoietic PPAR $\gamma$ was undertaken in $\gamma \mathrm{EC} / \mathrm{BM}-\mathrm{KO}$ mice using BMT, before repeating rosiglitazone treatment and studies on fat. BM either expressing or lacking PPAR $\gamma$ was transplanted into either Tie2Cre ${ }^{-}$(expressing endothelial PPAR $\gamma$ ) or Tie2Cre ${ }^{+}$ (lacking endothelial PPAR $\gamma$ ) mice to generate a full complement of mice either having or lacking PPAR $\gamma$ expression in BM and/or ECs: WT ( $\gamma$ EC-WT/BM-WT), BM-deficient only $(\gamma E C-W T / B M-$ $\mathrm{KO})$, EC-deficient only $(\gamma \mathrm{EC}-\mathrm{KO} / \mathrm{BM}-\mathrm{WT})$, or both EC- and BMdeficient ( $\gamma \mathrm{EC}-\mathrm{KO} / \mathrm{BM}-\mathrm{KO})$ mice. Two months after BMT, effective engraftment and reconstitution of PPAR $\gamma$ expression in hematopoietic cells was confirmed by RT-PCR in isolated splenic lymphocytes from relevant mice (Figure 5D). To summarize these findings, a significant decrease in epididymal fat pads tracked exactly with decreased endothelial PPAR $\gamma$ expression $(\gamma \mathrm{EC}-\mathrm{KO} / \mathrm{BM}-\mathrm{WT}$ and $\gamma \mathrm{EC}-\mathrm{KO} / \mathrm{BM}-\mathrm{KO}$ mice) and independently of hematopoietic PPAR $\gamma$ expression. Mice with either decreased or preserved hematopoietic 
A

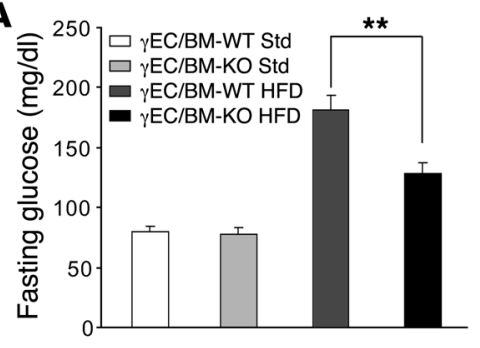

C

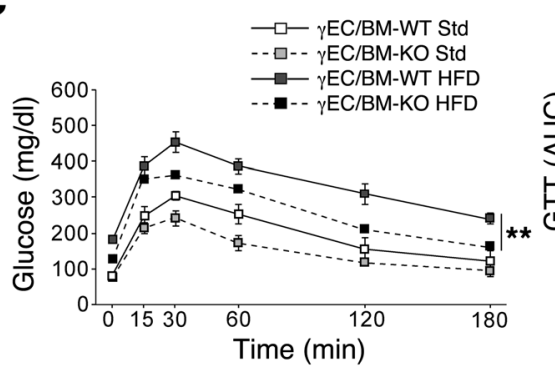

B
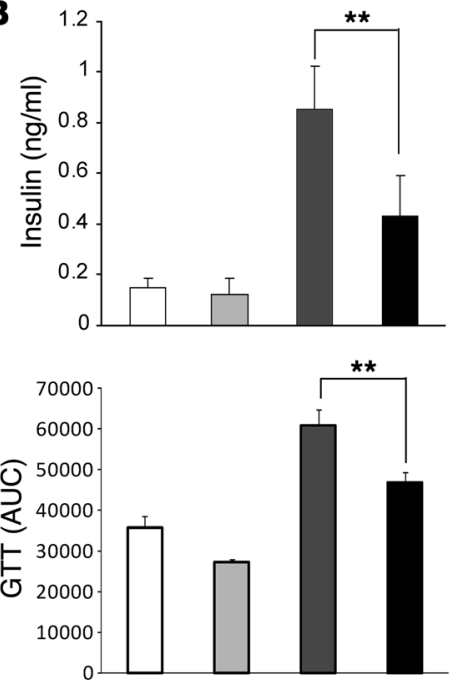

\section{Figure 3}

Tie2Cre-mediated PPAR $\gamma$ deletion improves glucose control and insulin sensitivity in response to high-fat diet. (A) Fasting glucose and (B) insulin levels and (C) glucose tolerance and $(D)$ insulin tolerance testing in $\gamma \mathrm{EC} / \mathrm{BM}-\mathrm{KO}$ and $\gamma \mathrm{EC} / \mathrm{BM}-\mathrm{WT}$ mice after standard chow or high-fat diet $(n=5-6)$. (C) The AUC of glucose levels during glucose tolerance tests is shown. ${ }^{\star} P<0.05$, ${ }^{* *} P<0.01$ versus obese $\gamma$ EC/BM-WT mice. GTT, glucose tolerance test.

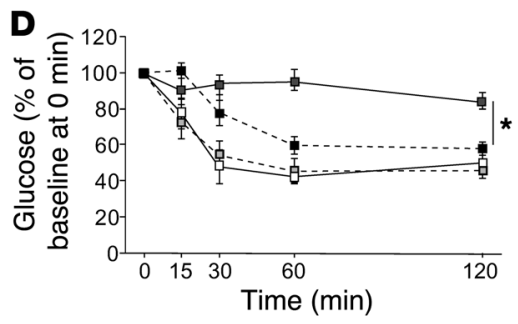

PPAR $\gamma$ expression but intact endothelial PPAR $\gamma(\gamma \mathrm{EC}-\mathrm{WT} / \mathrm{BM}-\mathrm{KO}$ and $\gamma \mathrm{EC}-\mathrm{WT} / \mathrm{BM}-\mathrm{WT}$ mice) had no change in epididymal fat mass (Figure 5D). These results indicate that endothelial PPAR $\gamma$ contributes to epididymal fat pad development.

We next studied a similar complement of endothelial and/or BM PPAR $\gamma$-deficient mice after high-fat diet feeding. In the absence of endothelial PPAR $\gamma(\gamma \mathrm{EC}-\mathrm{KO} / \mathrm{BM}-\mathrm{WT}$ and $\gamma \mathrm{EC}-\mathrm{KO} / \mathrm{BM}-\mathrm{KO}$ mice), inguinal and epididymal fat pads were significantly decreased as compared with mice with WT endothelial PPAR $\gamma$ and either PPAR $\gamma$ absent or present in the BM $(\gamma \mathrm{EC}-\mathrm{WT} / \mathrm{BM}-\mathrm{KO}$ and $\gamma \mathrm{EC}-\mathrm{WT} / \mathrm{BM}-$ WT mice; Figure 6A). Likewise, adipocyte size was significantly decreased only in mice lacking endothelial PPAR $\gamma$ and independently of hematopoietic PPAR y expression (Figure 6A). Consistent with earlier results without $\mathrm{BMT}$, liver and spleen weights were increased in $\gamma$ EC-KO/BM-WT and $\gamma$ EC-KO/BM-KO mice (Figure 6A). To more precisely identify whether endothelial PPAR $\gamma$ accounted for functional improvements in insulin sensitivity, insulin and glucose tolerance testing was repeated in a similar complement of BMT mice as used above, either expressing or lacking PPAR $\gamma$ in the endothelium or BM: WT ( $\gamma$ EC-WT/BM-WT), BM-deficient ( $\gamma$ ECWT/BM-KO), and EC-deficient ( $\gamma \mathrm{EC}-\mathrm{KO} / \mathrm{BM}-\mathrm{WT})$ mice or mice deficient in both ( $\gamma \mathrm{EC}-\mathrm{KO} / \mathrm{BM}-\mathrm{KO})$. Mice lacking PPAR $\gamma$ in the endothelium were more insulin sensitive and more glucose tolerant, independent of PPAR $\gamma$ BM expression (Figure 6B).

Endothelial PPAR $\gamma$ deletion is associated with increased serum FFA and $T G$ levels. The reduced adiposity, increased serum FFA and TG levels, and decreased TG accumulation in skeletal muscle in highfat diet-fed $\gamma \mathrm{EC} / \mathrm{BM}-\mathrm{KO}$ mice, changes that contrasted with the increase TG accumulation in the livers of these mice, suggested specific abnormalities in FA handling as a function of endothelial
PPAR $\gamma$. To investigate this, we measured serum FFA and TG levels in standard chow-fed $\gamma \mathrm{EC} / \mathrm{BM}-\mathrm{KO}$ and $\gamma \mathrm{EC} / \mathrm{BM}-\mathrm{WT}$ mice after feeding and 24 hours of fasting. In the fed state on standard chow, no significant difference in FFA or TG levels was observed in the presence or absence of Tie2Cre expression (Figure 7A). However, after 24 hours of fasting, mice with Tie2-mediated PPAR $\gamma$ deletion $(\gamma \mathrm{EC} / \mathrm{BM}-\mathrm{KO})$ manifested significantly increased FFA and TG levels (Figure 7A). The hypertriglyceridemia apparent in $\gamma \mathrm{EC} / \mathrm{BM}-$ $\mathrm{KO}$ mice after fasting derived mainly from elevated VLDL levels, as determined by HPLC; LDL levels were also increased, although to a lesser extent (Figure 7B). Total cholesterol and HDL-cholesterol levels were also increased in $\gamma \mathrm{EC} / \mathrm{BM}-\mathrm{KO}$ mice (Figure 7C).

The dynamic response to handling a lipid challenge may differ from what is seen in fed or fasted state. As such, we next tested the response to olive oil gavage in these mice $(21,22)$. Three hours after olive oil administration, $\gamma \mathrm{EC} / \mathrm{BM}-\mathrm{KO}$ mice had grossly obvious lactescent serum, with increased FFA and TG levels that failed to normalize 9 hours after challenge, all in striking contrast to $\gamma \mathrm{EC} / \mathrm{BM}-\mathrm{WT}$ controls (Figure 8A). The increase in TG levels in $\gamma \mathrm{EC} / \mathrm{BM}-\mathrm{KO}$ mice was mainly due to increased chylomicron (CM) and VLDL levels as seen on HPLC analysis (Figure 8B).

To determine if ECs, hematopoietic cells, or both were responsible for defective TG metabolism and FA handing in $\gamma \mathrm{EC} / \mathrm{BM}-\mathrm{KO}$ mice, we repeated olive oil gavage 8 weeks after BMT in a similar complement of groups as before (Figures 5 and 6). Defective FA uptake and TG metabolism occurred only in the absence of endothelial PPAR $\gamma$; decreased hematopoietic PPAR $\gamma$ expression had no impact on FFA and TG parameters (Figure 8C).

To further consider if FA uptake differed as a function of endothelial PPAR $\gamma$ expression in these mice, we analyzed FA 

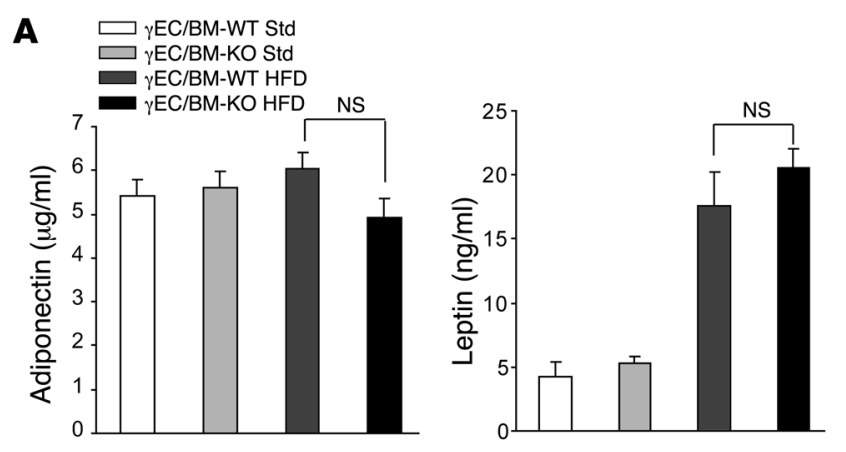

B $\begin{gathered}\text { Skeletal } \\ \text { muscle }\end{gathered} \underset{\gamma E C \text { EC/BM-WT HFO HFD }}{\gamma}$
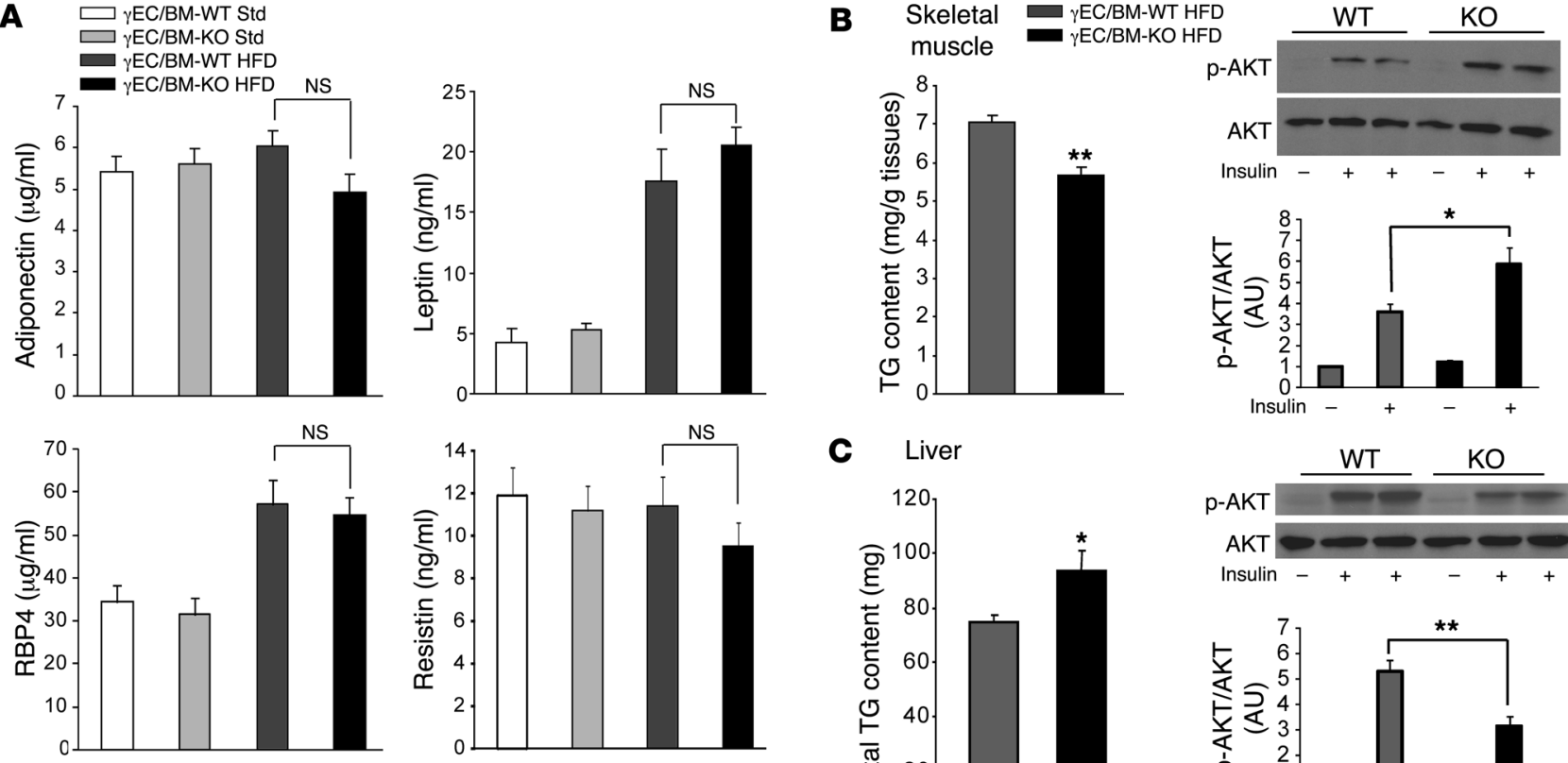

C
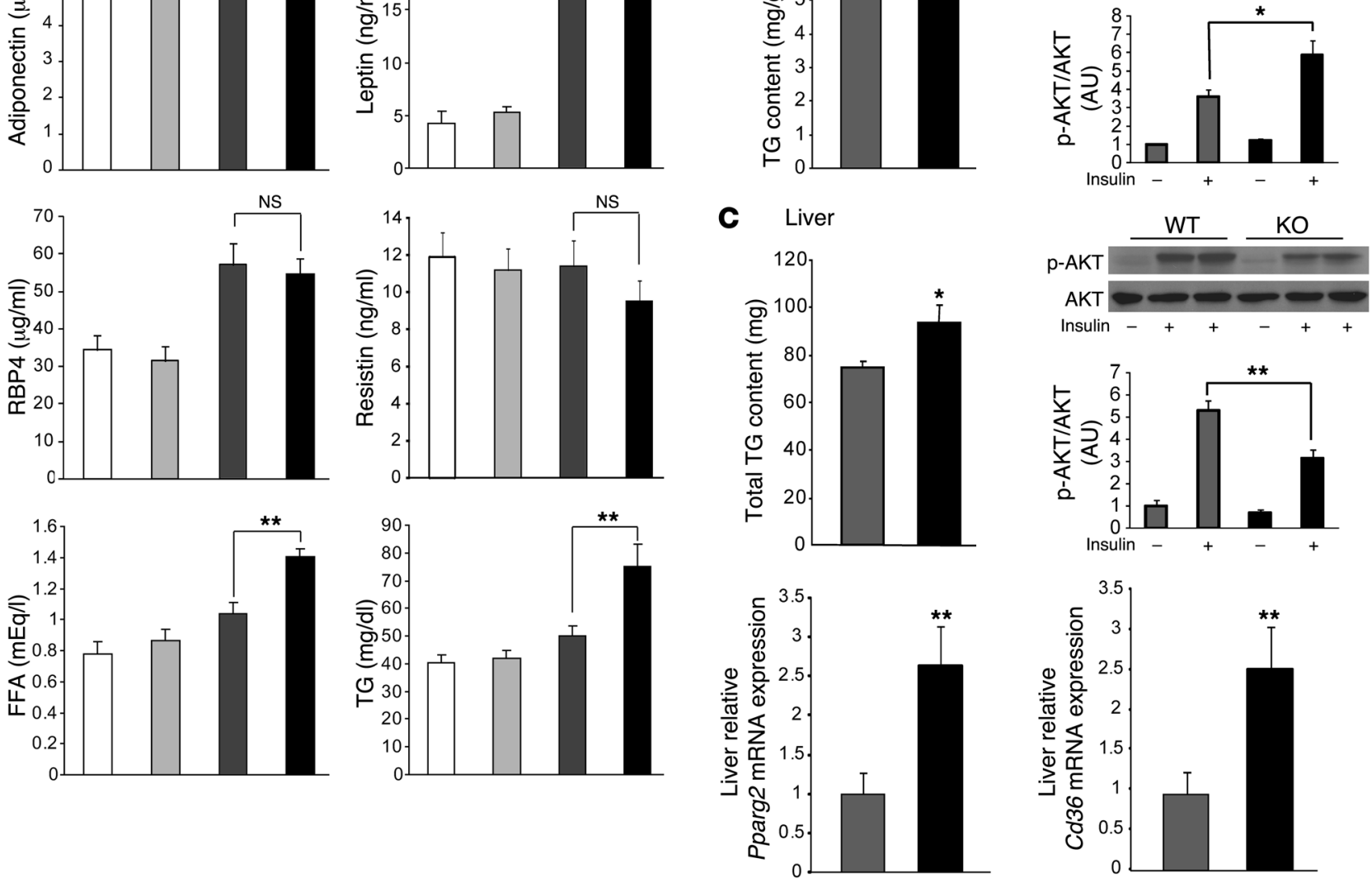

Figure 4

Tie2Cre-mediated PPAR $\gamma$ deletion increases serum FFA and TG levels but decreases TG deposition in skeletal muscle after high-fat diet feeding. (A) Serum levels of adiponectin, leptin, retinol binding protein 4 (RBP4), resistin, FFA, and TG in $\gamma E C / B M-K O$ and $\gamma E C / B M-W T$ mice after standard chow or high-fat diet $(n=4-9)$. (B) Skeletal muscle TG content in $\gamma E C / B M-K O$ and $\gamma E C / B M-W T$ mice after high-fat diet is shown (left panel; $n=5$ ). Western blotting and quantification of insulin-stimulated AKT serine 473 phosphorylation in skeletal muscle is shown (right panel; $n=3-6$ ). (C) Liver TG content in $\gamma \mathrm{EC} / \mathrm{BM}-\mathrm{KO}$ and $\gamma \mathrm{EC} / \mathrm{BM}-W T$ mice after high-fat diet is shown (left panel; $n=5$ ). Western blotting and quantification of insulin-stimulated AKT serine 473 phosphorylation in liver is shown (right panel; $n=3-6$ ). Real-time quantitative PCR analysis of $P p a r g 2$ and Cd36 expression in liver in $\gamma \mathrm{EC} / \mathrm{BM}-\mathrm{KO}$ and $\gamma \mathrm{EC} / \mathrm{BM}-\mathrm{WT}$ mice after high-fat diet $(n=5) .{ }^{*} P<0.05$, ${ }^{* *} P<0.01$ versus obese $\gamma \mathrm{EC} / \mathrm{BM}-\mathrm{WT}$ mice.

uptake in primary ECs isolated from $\gamma \mathrm{EC} / \mathrm{BM}-\mathrm{KO}$ and $\gamma \mathrm{EC} / \mathrm{BM}-$ WT mice before stimulation with rosiglitazone, a known inducer of increased FA uptake. As expected, rosiglitazone increased FA uptake in PPAR $\gamma$-expressing ECs from $\gamma \mathrm{EC} / \mathrm{BM}$-WT mice (Figure $8 \mathrm{D})$. In comparison, ECs from $\gamma \mathrm{EC} / \mathrm{BM}-\mathrm{KO}$ mice demonstrated significantly decreased FA uptake under either basal or rosiglitazone-stimulated conditions (Figure 8D).

Since PPAR $\gamma$ is a transcription factor, the phenotype of endothelial PPAR $\gamma$-deficient mice would be predicted to derive from changes in the expression of various endothelial gene targets, as suggested for PPAR $\gamma$ in other settings like adipocytes and macrophages. We found a series of known and novel PPAR $y$ target genes involved in FA handling and LPL function to be repressed in ECs isolated from $\gamma \mathrm{EC} / \mathrm{BM}-\mathrm{KO}$ mice. The PPAR $\gamma$-regulated transmembrane protein CD36, also known as FA translocase, is a long-chain FA receptor that facilitates FA uptake. Although CD36- deficient mice exhibit increased insulin sensitivity and less adiposity despite increased plasma FFA and TG levels (23-25), much like high-fat diet-fed $\gamma \mathrm{EC} / \mathrm{BM}-\mathrm{KO}$ mice (reviewed in ref. 23 ), a specific endothelial role for CD36 is not known. Both Cd36 mRNA and CD36 protein levels were decreased approximately $80 \%$ in ECs from $\gamma \mathrm{EC} / \mathrm{BM}-\mathrm{KO}$ versus $\gamma \mathrm{EC} / \mathrm{BM}$-WT mice (Figure $8 \mathrm{E}$ ). Importantly, these mice manifest altered expression of other genes involved in FA/TG handling, including the canonical PPAR $\gamma$-regulated adipocyte protein 2 (aP2 also known as FA-binding protein 4) as well as novel PPAR $\gamma$ targets glycosylphosphatidylinositol-anchored HDLbinding protein 1 (Gpibbp1), a cofactor for LPL action $(26,27)$, and the cellular retinol-binding protein III (CRBP-III, also known as RBP7 in mice and RBP5 in humans) that is expressed in ECs and is a member of the FA-binding protein family (28-30) (Figure 8F). Endothelial lipase expression was not altered, making it an unlikely contributor to the increased HDL-cholesterol and total cholesterol 
A

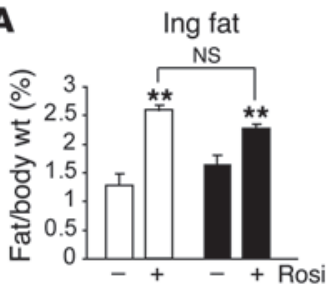

Epi fat

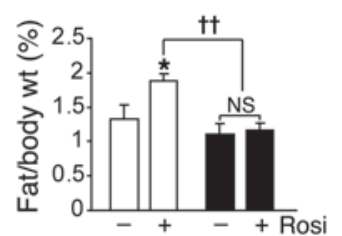

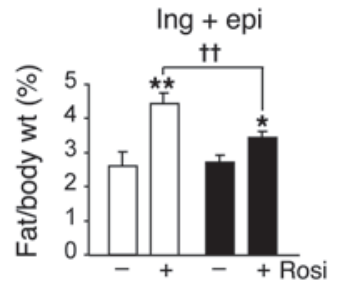

Brown adipose tissue

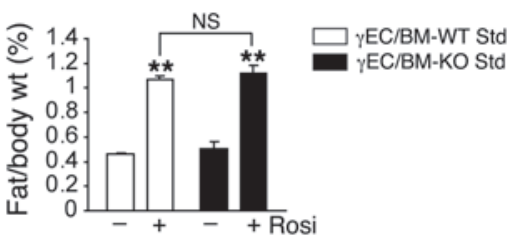

B

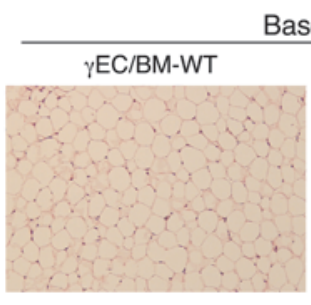

Baseline $\gamma E C / B M-K O$

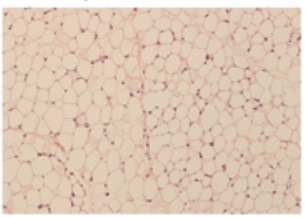

C

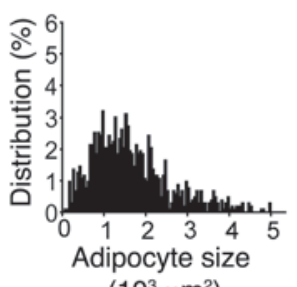

$\left(10^{3} \mu \mathrm{m}^{2}\right)$

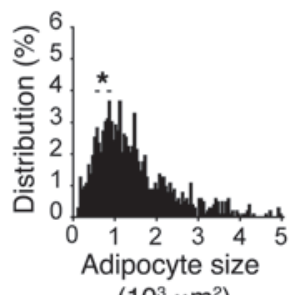

$\left(10^{3} \mu \mathrm{m}^{2}\right)$

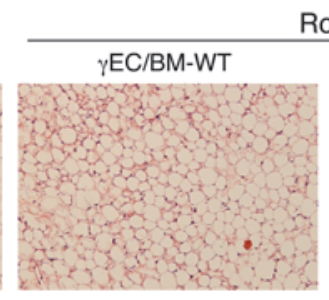

Rosi

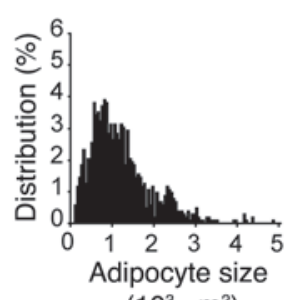

$\left(10^{3} \mu \mathrm{m}^{2}\right)$

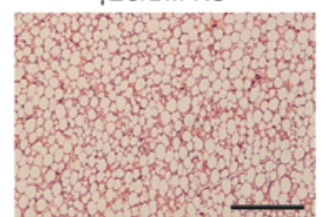

D
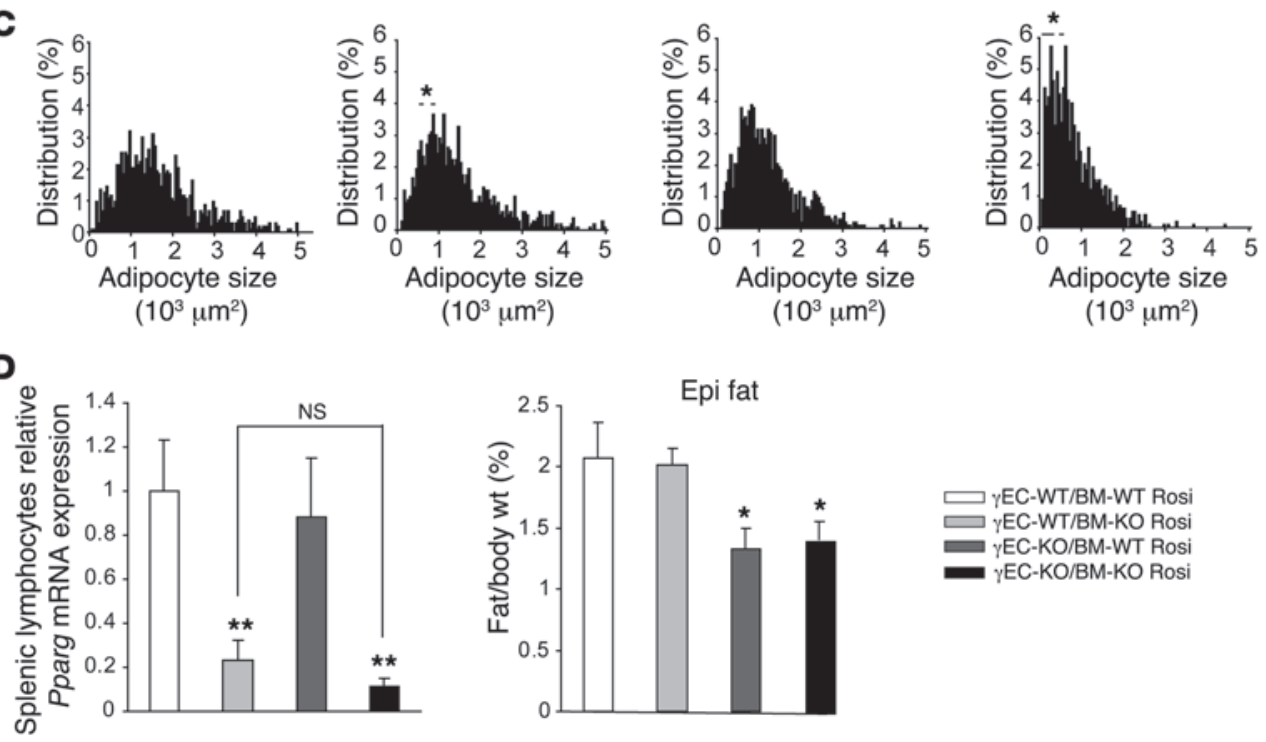

$\left(10^{3} \mu \mathrm{m}^{2}\right)$
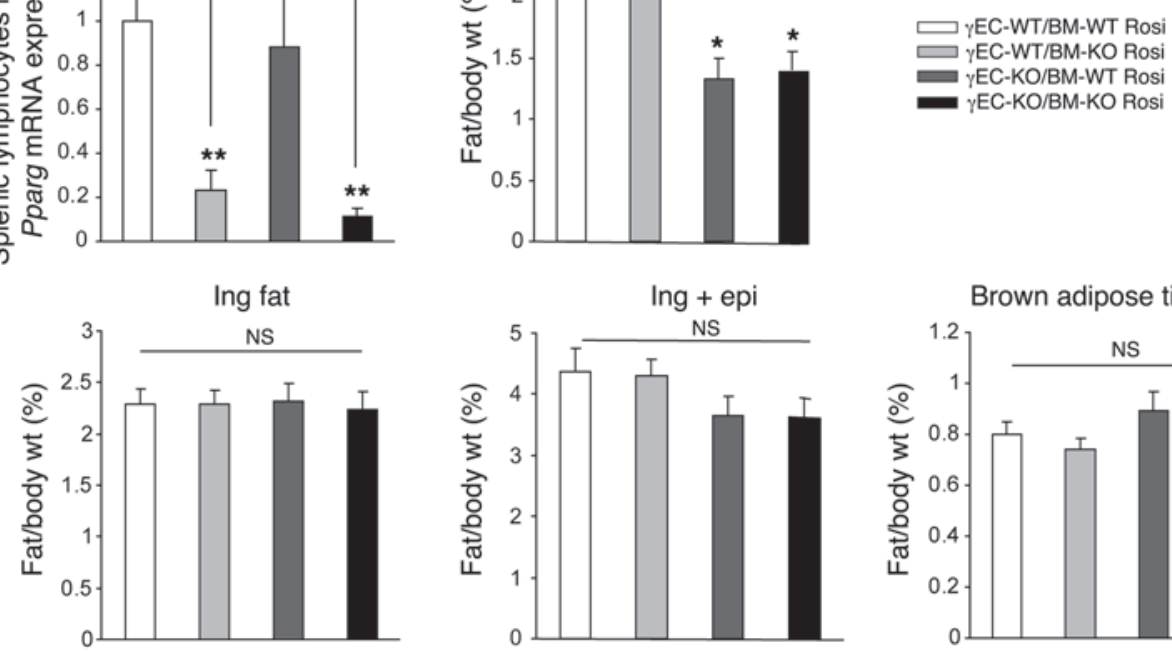

Figure 5

Tie2Cre-mediated PPAR $\gamma$ endothelial deletion decreases adiposity and adipocyte size in response to rosiglitazone treatment in a manner dependent on endothelial but not BM PPAR $\gamma$ expression. (A) Ratio of inguinal, epididymal, and brown adipose tissue weight/body weight in $\gamma E C / B M-$ $\mathrm{KO}$ and $\gamma \mathrm{EC} / \mathrm{BM}-\mathrm{WT}$ mice after rosiglitazone (Rosi) treatment when fed with a standard chow diet $(n=5-8) .{ }^{*} P<0.05,{ }^{\star \star} P<0.01$ versus same genotype mice. ${ }^{\dagger+} P<0.01$ versus $\gamma \mathrm{EC} / \mathrm{BM}-\mathrm{WT}$ mice treated with rosiglitazone. (B) Histology of inguinal adipose tissue from $\gamma \mathrm{EC} / \mathrm{BM}-\mathrm{WT}$ and $\gamma \mathrm{EC} / \mathrm{BM}-\mathrm{KO}$ mice from A treated with or without rosiglitazone. Scale bar: $200 \mu \mathrm{m}$. (C) Adipocyte size of inguinal adipose tissue from $\gamma E C / B M-K O$ and $\gamma$ EC/BM-WT mice from A treated with or without rosiglitazone. ${ }^{*} P<0.05$ versus $\gamma E C / B M-W T$ with same treatment. (D) Real-time quantitative PCR analysis of PPAR y expression in splenic lymphocytes isolated from mice after BMT ( $n=4-5 /$ group). Ratio of epididymal, inguinal, inguinal plus epididymal and brown adipose tissue weight/body weight after rosiglitazone treatment in BMT mice $(n=5-9)$. ${ }^{\star} P<0.05$, ${ }^{\star \star} P<0.01$ versus $\gamma$ EC-WT/BM-WT mice. 
A
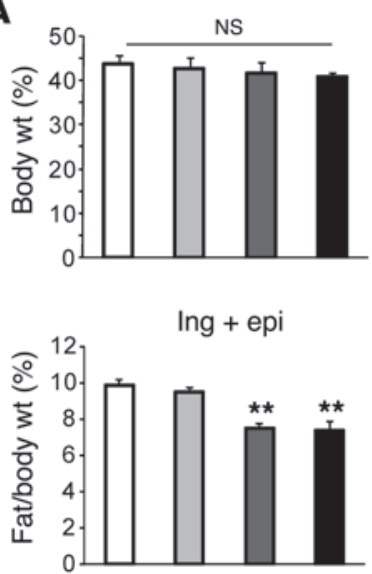

$\gamma$ EC-WT/BM-WT

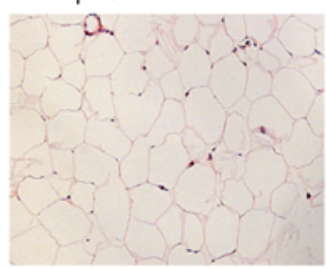

B
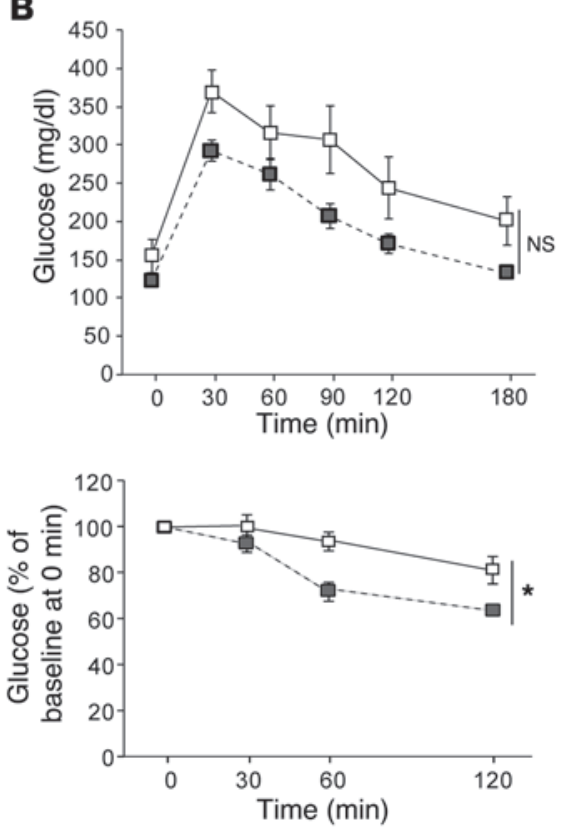

Ing fat
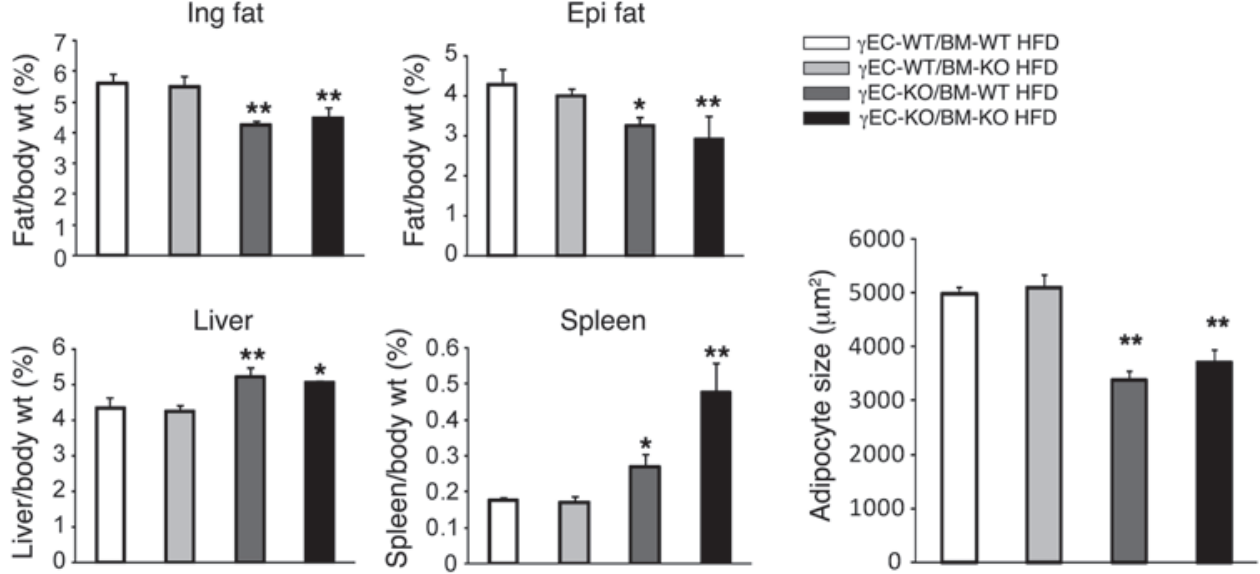

$\square \gamma$ EC-WT/BM-WT HFD
YEC-WT/BM-KO HFD
$\gamma$ EC-KO/BM-WT HFD
$\gamma E C-K O / B M-K O$ HFD

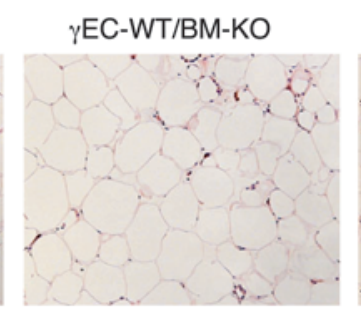

$\gamma$ EC-KO/BM-WT

\section{$\gamma \mathrm{EC}-\mathrm{KO} / \mathrm{BM}-\mathrm{KO}$}
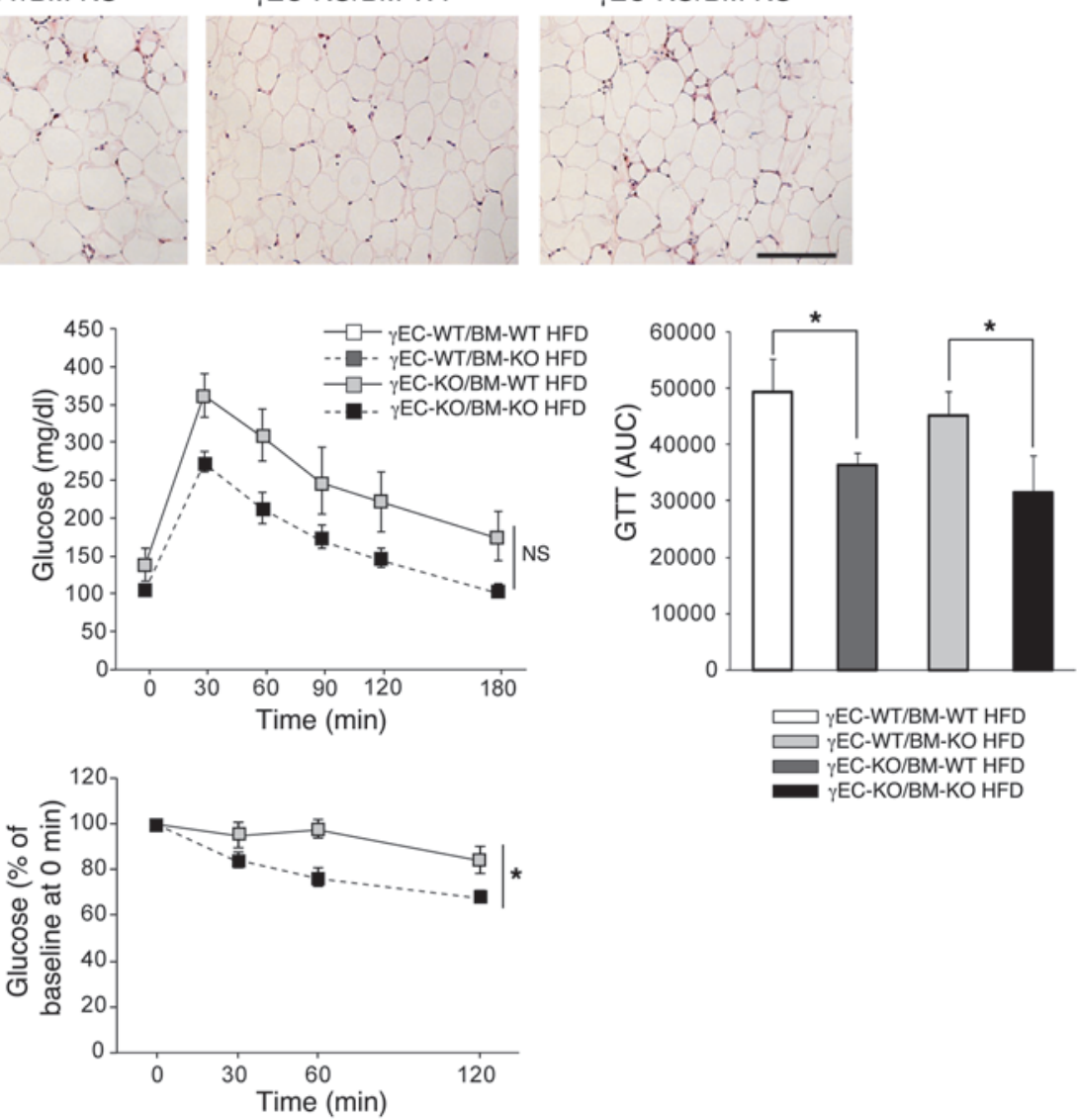

Figure 6

Tie2Cre-mediated PPAR $\gamma$ endothelial deletion decreases adiposity, adipocyte size, and insulin resistance after high-fat diet in a manner dependent on endothelial but not BM PPAR $\gamma$ expression. (A) Ratio of inguinal, epididymal, liver, and spleen weight/body weight after high-fat diet in BMT mice $(n=4-7)$. Histology of epididymal adipose tissue from BMT mice on high-fat diet as above. Scale bar: $200 \mu \mathrm{m}$. Mean adipocyte size in BMT mice on high-fat diet ( $n=4-7 /$ group). ${ }^{*} P<0.05,{ }^{*} P<0.01$ versus $\gamma$ EC-WT/BM-WT mice. (B) Glucose tolerance and insulin tolerance testing in BMT mice on high-fat diet $(n=4-7)$. AUC of glucose levels during glucose tolerance tests is shown. ${ }^{*} P<0.05 \gamma \mathrm{BM}-\mathrm{WT}$ or $\gamma \mathrm{BM}-\mathrm{KO}$ transplanted into EC-KO mice versus $\gamma \mathrm{BM}-\mathrm{WT}$ or $\gamma \mathrm{BM}-\mathrm{KO}$ into $\gamma \mathrm{EC}-\mathrm{WT}$ mice, respectively.

levels noted earlier (Figure 7C). Together these results suggest that endothelial PPAR $\gamma$ deficiency alters metabolic phenotype through specific changes in an endothelial PPAR $\gamma$ transcriptional cassette that coordinates FA handling and TG metabolism.
Increased serum FFA levels in $\gamma E C / B M-K O$ mice increase VLDL production and inbibit LPL activity. Elevated serum FFAs increase TG levels in 2 ways - by increasing VLDL production (31) and by inhibiting activity of LPL, a key enzyme in TG metabolism that hydrolyzes cir- 
A
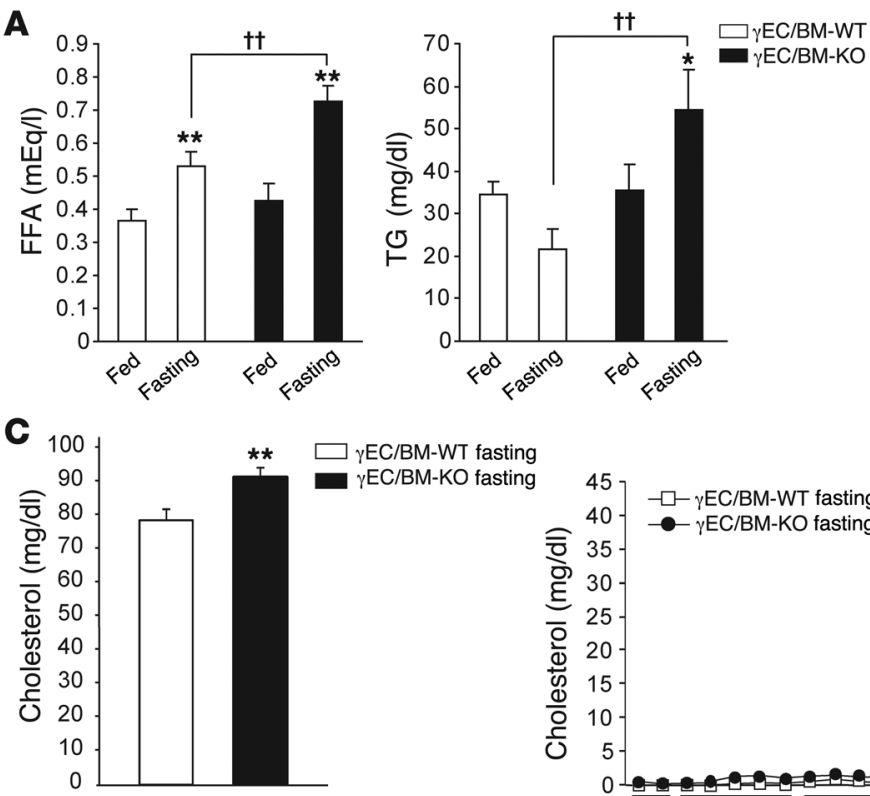

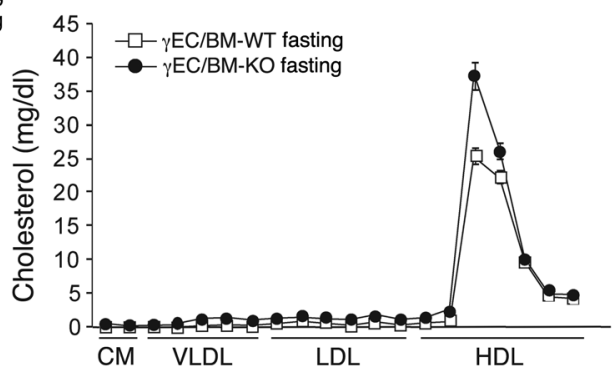

Figure 7

Endothelial PPAR $\gamma$ deletion increases TG and FFA levels after fasting. (A) FFA and TG concentrations were determined in fed and fasted (24 hours, throughout) $\gamma \mathrm{EC} / \mathrm{BM}-\mathrm{WT}$ and $\gamma \mathrm{EC} / \mathrm{BM}-\mathrm{KO}$ mice $\left(n=6 /\right.$ genotype). ${ }^{*} P<0.05 ;{ }^{* *} P<0.01$ versus same genotype in fed state. ${ }^{+t} P<0.01$ versus fasted $\gamma \mathrm{EC} / \mathrm{BM}-\mathrm{WT}$ mice. (B) Lipoprotein profiles after fasting ( $n=4 /$ genotype). (C) Total cholesterol concentration in fasted $\gamma \mathrm{EC} / \mathrm{BM}-\mathrm{WT}$ and $\gamma \mathrm{EC} / \mathrm{BM}-\mathrm{KO}$ mice $(n=10 /$ genotype $) .{ }^{* *} P<0.01$ versus $\gamma \mathrm{EC} / \mathrm{BM}-\mathrm{WT}$ mice. Lipoprotein profiles of cholesterol after fasting ( $n=4 /$ genotype).

culating CM and VLDL where it encounters them in its position on the endothelial surface $(21,22,32)$. To examine the mechanism for increased CM and VLDL levels in $\gamma \mathrm{EC} / \mathrm{BM}-\mathrm{KO}$ mice, we undertook more detailed studies of TG metabolism. Triton infusion inhibits LPL activity, allowing measurement of TG levels and VLDL production (33). In response to triton, fasted $\gamma \mathrm{EC} / \mathrm{BM}-\mathrm{KO}$ mice had higher TG levels and VLDL production rates than WT controls (Figure 9A). After olive oil gavage, serum FFA and TG levels were tightly correlated in $\gamma \mathrm{EC} / \mathrm{BM}-\mathrm{KO}$ and $\gamma \mathrm{EC} / \mathrm{BM}-\mathrm{WT}$ mice (Figure 9B, $r=0.85$; $P=0.0001)$. These changes between $\gamma \mathrm{EC} / \mathrm{BM}-\mathrm{KO}$ and $\gamma \mathrm{EC} / \mathrm{BM}-\mathrm{WT}$ mice were not a result of changes in relative $L p l$ mRNA expression in adipose tissue or skeletal muscle (Figure 9C). However, post-heparin LPL activity, but not hepatic lipase (HL) activity, was decreased in mice with Tie2-mediated PPAR $\gamma$ deletion versus controls (Figure 9D, left panel). When this assay was repeated in the presence of FA-free albumin, which binds FFAs and removes their effects, this inhibition of LPL activity in $\gamma \mathrm{EC} / \mathrm{BM}-\mathrm{KO}$ mice was no longer seen (Figure 9D, right panel). Together these results establish that the dyslipidemia in the $\gamma \mathrm{EC} / \mathrm{BM}-\mathrm{KO}$ mouse derives from increased VLDL production and decreased LPL activity in response to elevated FFA levels.

Tie2Cre-mediated PPAR $\gamma$ deletion diminishes the effect of rosiglitazone treatment after olive oil gavage. PPAR $\gamma$ agonists in clinical use lower FFA levels and increase FA uptake. To assess the role of endothelial PPAR $\gamma$ in these responses in vivo, we repeated olive oil gavage experiments, measuring FFA (Figure 10A) and TG (Figure 10B) levels but now after rosiglitazone treatment of $\gamma \mathrm{EC} / \mathrm{BM}-\mathrm{KO}$ and $\gamma \mathrm{EC} / \mathrm{BM}-\mathrm{WT}$ mice. As expected, rosiglitazone significantly lowered FFA and TG levels in $\gamma E C / B M-W T$ mice receiving this lipid load. In contrast, rosiglitazone had no effect on either FFA or TG levels in mice with Tie2-mediated PPAR $\gamma$ deletion.
Tie2Cre-mediated PPAR $\gamma$ deletion is associated with impaired vascular relaxation. The decreased adiposity and insulin resistance seen in Tie2-PPAR $\gamma$-deficient mice on a high-fat diet raises the question of whether vascular responses in these mice would also differ given reports of PPAR $\gamma$-mediated vascular benefits $(10,34)$. Tie2-PPAR $\gamma-$ deficient mice manifest hypertension in response to high-fat diet (11), but specific vasodilation studies have not been performed. To do so, we studied vascular reactivity in carotid arteries isolated from $\gamma E C / B M-K O$ and $\gamma E C / B M-W T$ mice under standard and high-fat diets. Although no difference was seen between arterial responses to carbachol after mice were fed a standard chow diet, high-fat diet-fed Tie2-deficient PPAR $\gamma$ mice had impaired arterial relaxation as compared with control mice (Figure 11). These data indicate endothelial PPAR $\gamma$ regulates metabolic responses in ways that are distinct from local endothelial PPAR $\gamma$ effects on the arterial wall (Figure 11).

\section{Discussion}

The role of the endothelial organ in governing physiologic homeostasis and fostering disease pathogenesis is now recognized (1). In insulin resistance and diabetes, endothelial dysfunction is a common and early finding thought to be promoted by factors such as dyslipidemia, elevated FFAs, hypertension, and obesity (35). To date, endothelial dysfunction has been understood in terms of abnormal vasomotor function. Specific mechanisms linking changes in the endothelium to subsequent issues with obesity and insulin resistance have not been well described. In the present study, we demonstrate that the transcription factor PPAR $\gamma$ plays, to our knowledge, a previously unrecognized role in the endothelium integrating FA handling, TG-rich lipoprotein metabolism, 
A
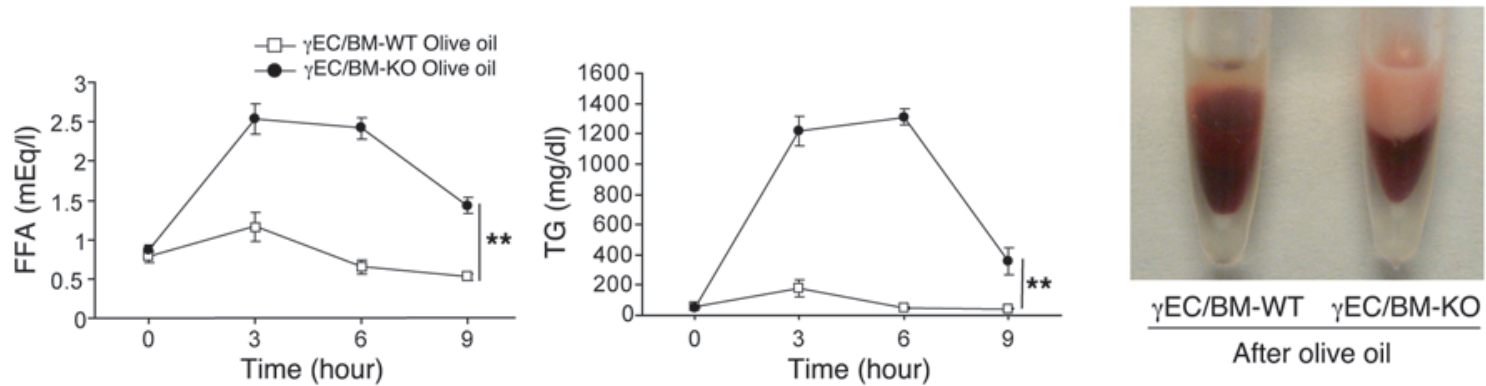

B
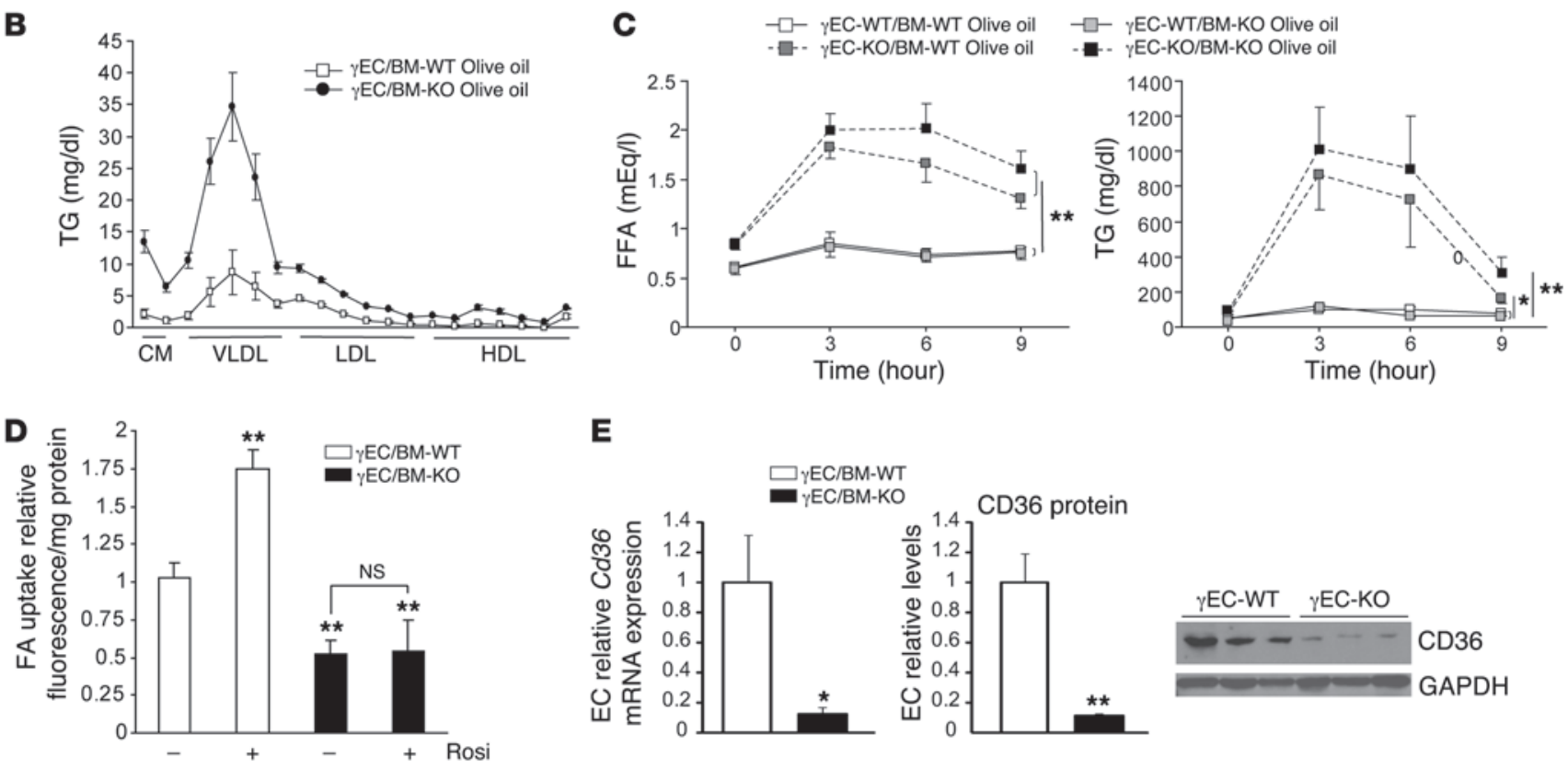

$\mathbf{E}$
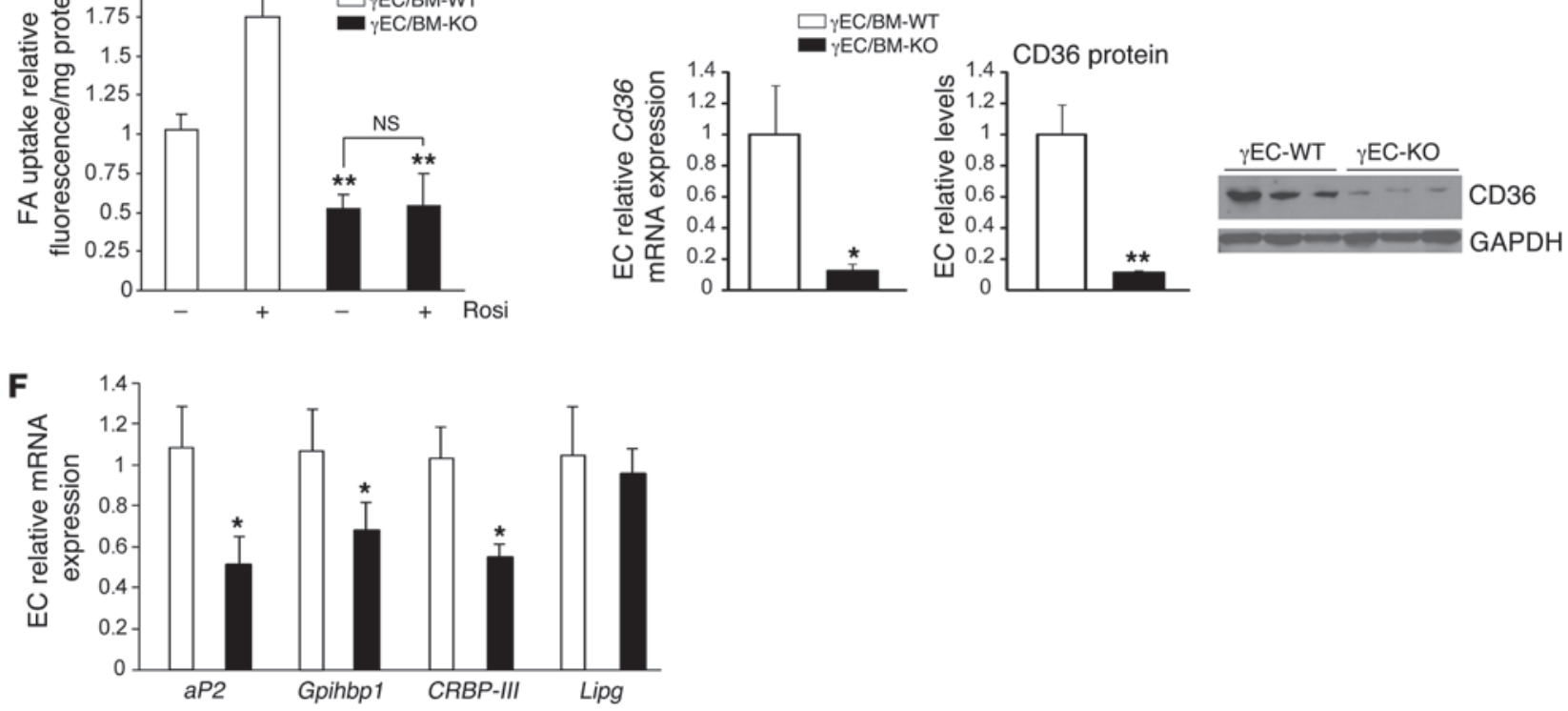

Figure 8

Endothelial PPAR $\gamma$ deletion increases TG and FFA levels after olive oil gavage independent of hematopoietic PPAR $\gamma$ expression. (A) Representative blood samples and FFA and TG concentrations in standard chow-fed $\gamma E C / B M-W T$ and $\gamma E C / B M-K O$ mice after overnight fasting, followed by olive oil gavage ( $n=6-8 /$ genotype). ${ }^{*} P<0.01$ versus $\gamma E C / B M-W T$. (B) Lipoprotein profiles 3 hours after olive oil gavage $(n=3 / g e n o t y p e)$. (C) FFA and TG concentration after olive oil feeding in mice after $\gamma$ BM-WT or $\gamma$ BM-KO BMT into EC-KO or EC-WT mice $(n=5-7 / g e n o t y p e)$. ${ }^{*} P<0.05$, ${ }^{\star \star} P<0.01$ over time course versus $\gamma$ BM-WT into $\gamma$ EC-WT mice. (D) Uptake of a fluorescently labeled long-chain FA (BODIPY-dodecanoic acid) by primary microvascular ECs from $\gamma \mathrm{EC} / \mathrm{BM}-\mathrm{KO}$ and $\gamma \mathrm{EC} / \mathrm{BM}-\mathrm{WT}$ mice measured without or with rosiglitazone stimulation ( $n=5,6 / \mathrm{genotype}$ ). ${ }^{* *} P<0.01$ versus ECs from $\gamma E C / B M-W T$ without rosiglitazone. (E) Cd36 mRNA expression (real-time quantitative PCR) and protein levels in microvascular ECs ( $n=3-5 /$ genotype). One representative Western blot is shown at right. ${ }^{\star} P<0.05,{ }^{* \star} P<0.01$ versus $\gamma \mathrm{EC} / \mathrm{BM}-\mathrm{WT}$ mice. (F) Expression of genes in endothelial cells of $\gamma \mathrm{EC} / \mathrm{BM}-\mathrm{KO}$ versus $\gamma \mathrm{EC} / \mathrm{BM}-\mathrm{WT}$ mice. $(n=5,6 /$ genotype $){ }^{*} P<0.05,{ }^{* *} P<0.01$ versus $\gamma \mathrm{EC} / \mathrm{BM}-\mathrm{WT}$ mice.

adiposity, and insulin sensitivity as well as arterial vasoreactivity in response to high-fat diet and acute lipid challenges (Figure 12). Mice lacking endothelial PPAR $\gamma$ manifest increased FFA levels, decreased fat accumulation in muscle, and increased insulin sensitivity in response to high-fat diet feeding, while also demonstrating abnormal handling of an oral lipid load. The metabolic phenotype of these mice tracks specifically with endothelial PPAR $\gamma$ deficiency and is completely independent of the presence or absence of PPAR $\gamma$ in the BM. Moreover, mice deficient in endothelial PPAR $\gamma$ have a diminished response to the PPAR $\gamma$ agonist rosiglitazone, lacking 


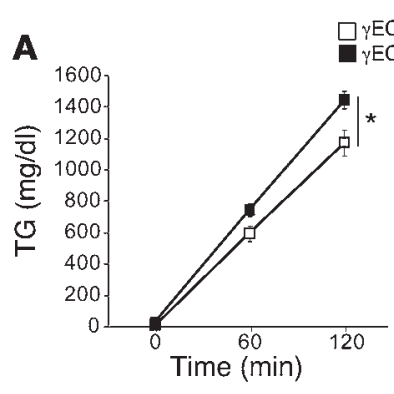

BM-WT fasting + triton C/BM-KO fasting + triton
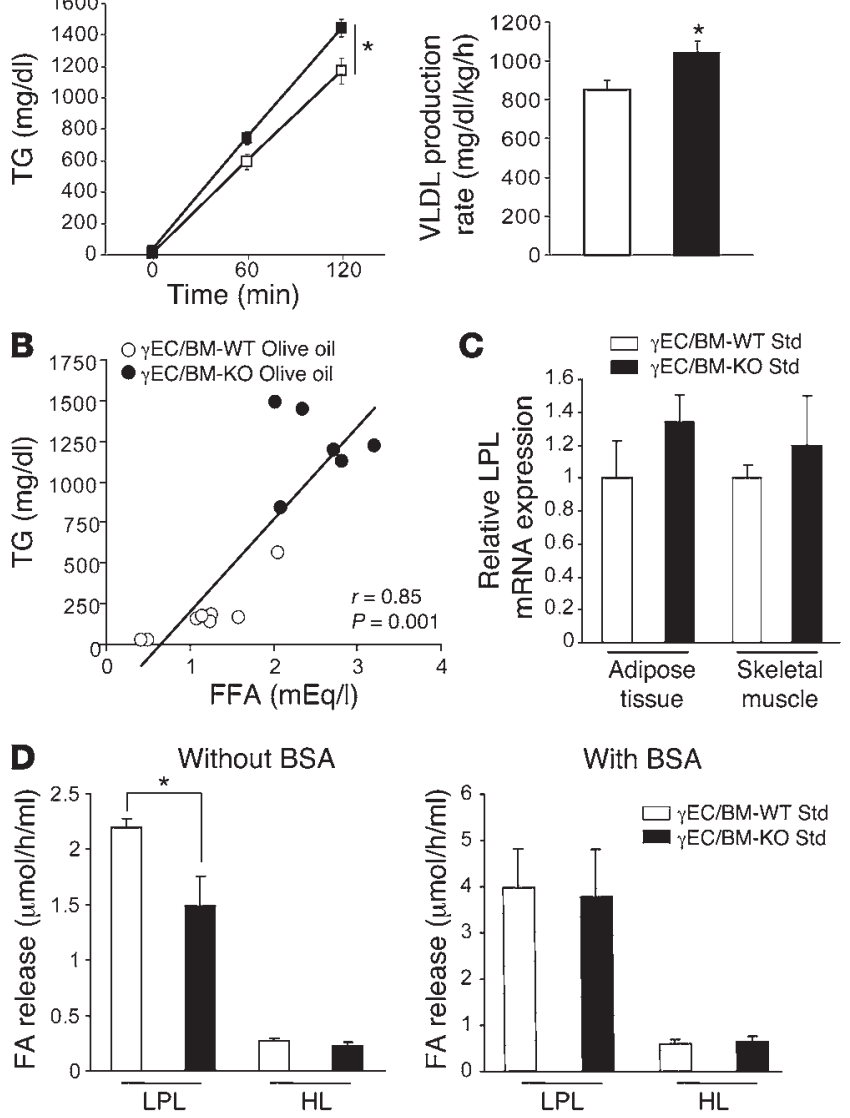

the known decrease in FFA or TG levels or increase in adipogenesis seen with this drug in mice and humans (18, 36-38).

In terms of FA handling and TG metabolism, hydrolysis of TGrich lipoproteins such as CM and VLDL occurs on the endothelial surface, where these lipoprotein particles encounter specific lipases like LPL. Liberated FAs are delivered into tissues with a high metabolic capacity for FA, either for storage, as in adipose tissue, or for energy combustion, as in heart and skeletal muscle $(39,40)$. Most attention has focused on the endothelium as a platform upon which TG-rich lipoprotein/lipase interaction occurs, with released FAs transversing the endothelium to reach tissues. Circulating FAs can also be released directly from their association with albumin (41). Although passive FA movement through membranes may occur, active transmembrane FA movement involves membrane-associated proteins such as CD36 and aP2 (42). We show here that modulation of PPAR $\gamma$ levels in the endothelium alone is sufficient to alter FA handling in vitro and in vivo, with systemic consequences on adiposity and insulin sensitivity (Figure 12). Just as PPAR $\gamma$ regulates multiple target genes in adipocytes to exert its functional effects, endothelial PPAR $\gamma$ appears to regulate coordinately an endothelial transcriptional cassette, involving both known and novel PPAR $\gamma$-regulated target genes, including Cd36, aP2, Gpibbp1, and CRBP-III.

The altered TG and FA metabolism seen in $\gamma \mathrm{EC} / \mathrm{BM}-\mathrm{KO}$ mice involves endothelial changes in the FA transporter CD36. Although CD36 has been extensively studied, a role for the endothelium in explaining CD36 biology in vivo has not been previously appreci-

\section{Figure 9}

Tie2Cre-mediated PPARy deletion increases VLDL production rate and inhibits LPL activity. (A) TG concentrations and calculated VLDL production rate after triton injection in fasted (24 hours) $\gamma E C / B M-W T$ and $\gamma$ EC/BM-KO mice ( $n=5 /$ genotype). ${ }^{*} P<0.05$ versus $\gamma$ EC/BM-WT. (B) Correlation between serum FFA levels and TG levels in fasted $\gamma \mathrm{EC} / \mathrm{BM}-\mathrm{WT}$ (white circles) and $\gamma \mathrm{EC} / \mathrm{BM}-\mathrm{KO}$ (black circles) mice ( $n=6-8 /$ genotype) 3 hours after olive oil gavage. (C) Real-time quantitative PCR analysis of $L p /$ mRNA expression in white adipose tissue and skeletal muscle from $\gamma \mathrm{EC} / \mathrm{BM}-\mathrm{WT}$ and $\gamma \mathrm{EC} / \mathrm{BM}-\mathrm{KO}$ mice when fed with a standard chow diet. (D) Post-heparin LPL and HL activity 3 hours after olive oil feeding, in the absence (left panel) or presence (right panel) of excess FFA-free BSA $(n=6-8) .{ }^{*} P<0.05 \gamma \mathrm{EC} / \mathrm{BM}-\mathrm{KO}$ versus $\gamma \mathrm{EC} / \mathrm{BM}-\mathrm{WT}$ mice.

ated. Like $\gamma$ EC/BM-KO mice, CD36-deficient mice have increased insulin sensitivity and reduced adiposity despite elevated FFA levels (23-25). At the same time, important divergences exist between endothelial PPAR $\gamma$-deficient and CD36-deficient mice. In the case of CD36 deficiency, FFA flux to the liver is increased, which precipitates hepatic steatosis, but without evidence for increased VLDL production $(21,22,24)$. This is particularly interesting, since increased FFA levels stimulate increased VLDL production in the liver (31), as evident in hepatic CD36 overexpression (43). Mice that lack endothelial PPAR $\gamma$ have decreased endothelial CD36 levels elsewhere but increased hepatic CD36 expression and increased VLDL production (Figure 12). However, the changes in FA and TG handling in these mice also appear to involve other PPAR $\gamma$-regulated endothelial targets. aP2 is a canonical PPAR $\gamma$ target gene involved in FA transport. GPIHBP1 is a recently described protein found to influence TG levels by serving as a novel cofactor for LPL $(26,27)$. CRBP-III (RBP7) is a retinoid-binding/lipid droplet protein, whose functional effects, including participation in FA efflux, may be driven by its EC expression patterns (28-30). Together these differences strongly support the endothelium as an organ that can influence systemic metabolic responses in a precise tissue- and organ-specific manner.

Tissues with high energy, and hence FA, requirements, like cardiac and skeletal muscle, contain nonfenestrated endothelium (40). In these organs, the ECs lining the microvascular compartment form a major transport barrier for circulating FFAs. The liver contains a fenestrated endothelium, which allows intact diffusion of the FA-albumin complex into the spaces of Disse and the interstitial compartment (40). In the hepatic setting, plasma FA concentration correlates directly with FA influx (44). In mice with Tie2-mediated PPAR $\gamma$ deletion, lipid accumulation was reduced in skeletal muscle and adipose tissue, but not liver, with associated increases in hepatic VLDL production (Figure 12). Since PPAR $\gamma$ agonists increase lipid accumulation in both adipose tissue and skeletal muscle $(45,46)$, the lack of these responses in Tie2-mediated PPAR $\gamma$-deficient mice further identifies endothelial PPAR $\gamma$ as an important but previously overlooked determinant of adiposity.

PPAR $\gamma$ activation promotes adipose tissue expansion by stimulating adipogenesis, increasing the number of small, younger adipocytes and the capacity of adipocytes to store lipids. These responses are inhibited in mice lacking endothelial PPAR $\gamma$ after high-fat diet feeding or rosiglitazone treatment (Figures 2, 5, and 6). In this sense, our data integrate well with the findings of Kubota and colleagues, who found that heterozygous PPAR $\gamma$ deficiency resulted in mice with smaller, more insulin sensitive adipocytes 

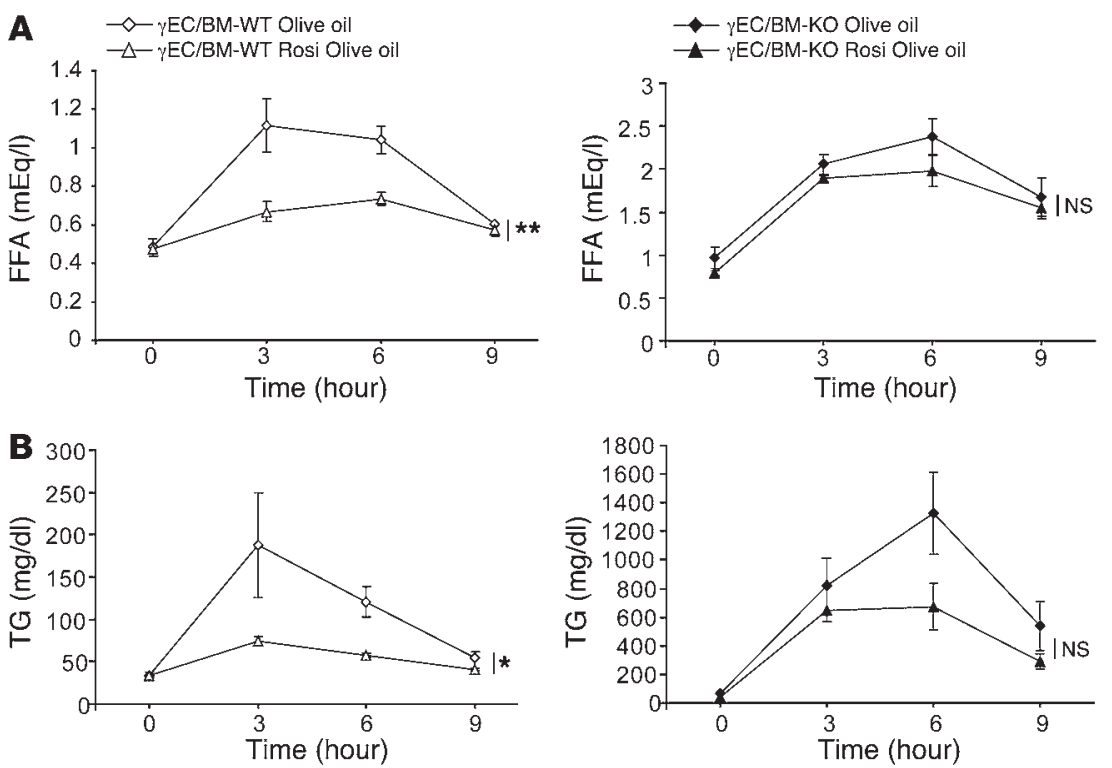

\section{Figure 10}

Rosiglitazone fails to lower FA and TG levels after lipid challenge in $\gamma \mathrm{EC} / \mathrm{BM}-\mathrm{KO}$ mice as compared with $\gamma E C / B M-W T$ mice. (A) FFA and (B) TG concentrations after olive oil gavage in $\gamma E C / B M-W T$ (left panels) and $\gamma \mathrm{EC} / \mathrm{BM}-\mathrm{KO}$ (right panels) mice on standard chow diet with or without rosiglitazone treatment ( $n=5-8 /$ genotype). ${ }^{*} P<0.05$, ${ }^{\star \star} P<0.01$ for entire curve, versus same genotype without rosiglitazone. and less adiposity but increased FFA influx to the liver and not to muscle $(47,48)$. Our data raise the possibility that changes in endothelial PPAR $\gamma$ target genes may have contributed to the phenotype of heterozygous PPAR $\gamma$ deficiency. Interestingly, spontaneously hypertensive rats that have a defective form of CD36 demonstrate decreased adipogenesis in response to rosiglitazone (49).

Endothelial PPAR $\gamma$ deficiency influenced adiposity in a depotspecific manner, with epididymal and inguinal subcutaneous adipose tissue expanding differently after high-fat diet feeding and rosiglitazone treatment in $\gamma \mathrm{EC} / \mathrm{BM}-\mathrm{KO}$ versus $\gamma \mathrm{EC} / \mathrm{BM}-\mathrm{WT}$ mice (Figures 2, 5, and 6). Interestingly, similar patterns have been reported with PPAR $\gamma$ agonists in human studies $(36,37,50)$. TZDs strongly promote differentiation of human preadipocytes isolated from subcutaneous but not visceral fat (50) and increase the number of small adipocytes exclusively in subcutaneous fat (51). Our findings suggest the endothelium may help determine adipose depot-specific responses to PPAR $\gamma$ activation. These data also raise the intriguing possibility that PPAR $\gamma$ in the endothelium may help determine clinical TZD responses $(49,52)$, since known effects of rosiglitazone in various nutrients states, including post-lipid challenge, were dependent on endothelial PPAR $\gamma$ expression.

Endothelial PPAR $\gamma$ deletion also increased insulin sensitivity (Figure 3). FFA and insulin sensitivity are negatively correlated (53), with increased FA and TG accumulation in muscle considered an early step in the development of insulin resistance (17). Obese $\gamma \mathrm{EC} / \mathrm{BM}-\mathrm{KO}$ mice have reduced TG accumulation in skeletal muscle despite their increased serum FFA and TG levels (Figure 4). Skeletal muscle in mice lacking endothelial PPAR $\gamma$ have increased insulin-stimulated AKT phosphorylation, which has been strongly associated with increased insulin sensitivity. In direct contrast, $\gamma \mathrm{EC} / \mathrm{BM}-\mathrm{KO}$ mice had decreased AKT phosphorylation in the liver, consistent with their increased hepatic FA uptake and TG accumulation. Recent work suggests that TG accumulation may only be a marker for insulin resistance that derives from specific FA intermediates (54). Investigation of this issue in $\gamma \mathrm{EC} / \mathrm{BM}-\mathrm{KO}$ mice will be of particular interest as would any change in skeletal muscle blood flow as a potential contributor to insulin sensitivity. Of note, insulin sensitivity in $\gamma \mathrm{EC} / \mathrm{BM}-\mathrm{KO}$ mice may be offset by their chronically increased FFA levels, which can inhibit lipases and activate toll-like receptor 4 , which promotes insulin resistance (55). Such factors may mitigate the net changes in glucose metabolism that occur as a function of endothelial PPAR $\gamma$.

The Tie 2 promoter drives expression in both ECs and BMderived hematopoietic cells $(12,13)$. Our BMT data establish that mice lacking endothelial PPAR $\gamma$ have a persistent metabolic phenotype independent of hematopoietic $\operatorname{PPAR} \gamma$, an area of recent controversy. Rosiglitazone has been reported to promote transdifferentiation of BM-derived circulating progenitor cells into

\section{Figure 11}

Tie2Cre-mediated PPAR $\gamma$ deletion impairs vasodilation in arteries from mice fed high-fat diet. Vascular responses were measured in arterial preparations isolated from $\gamma E C / B M-W T$ and $\gamma E C / B M-K O$ mice fed standard chow (A) or high-fat diet (B). Percent dilation of left common carotid arteries after phenylephrine preconstriction $\left(10^{-5} \mathrm{M}\right)$, followed by increasing doses of carbachol $(n=4-5)$. ${ }^{\star} P<0.05,{ }^{* *} P<0.01$ versus $\gamma \mathrm{EC} / \mathrm{BM}-\mathrm{WT}$ mice under similar dietary conditions.
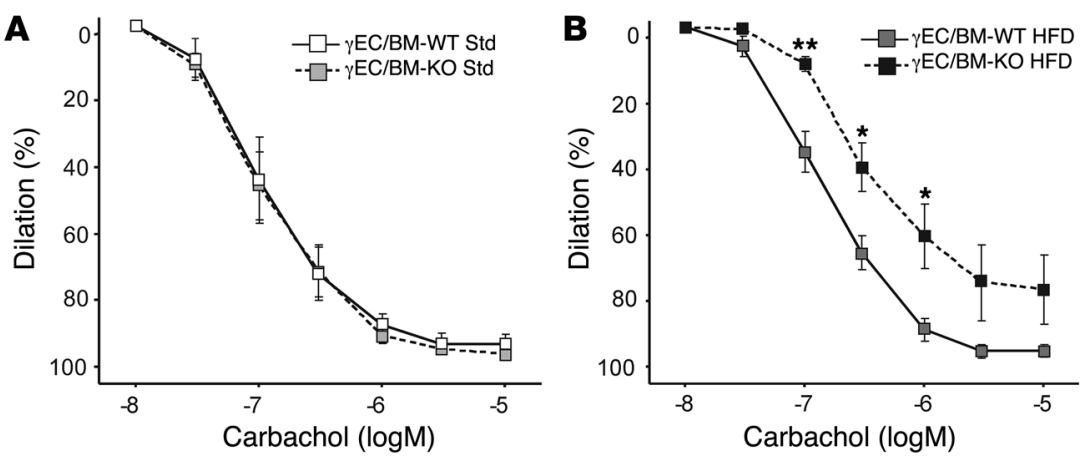


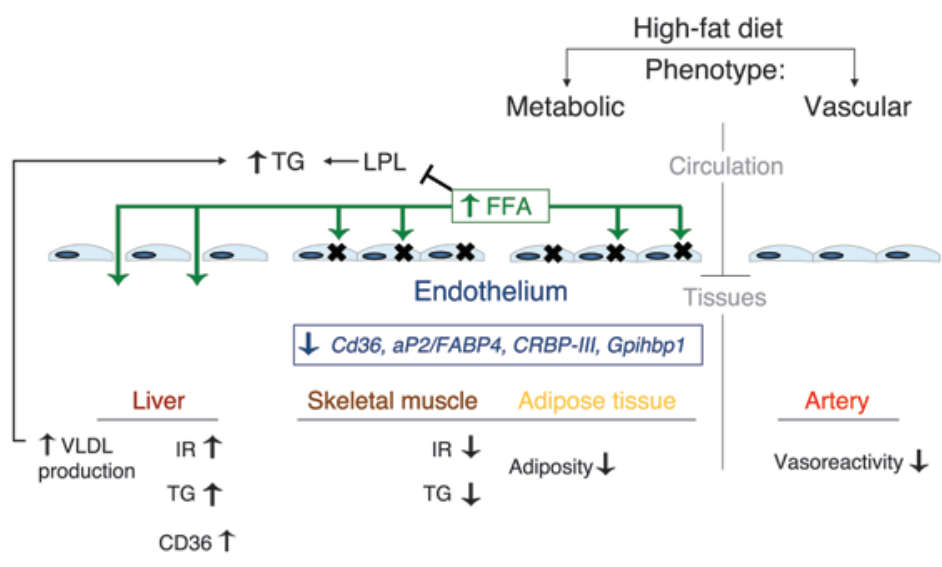

Figure 12

PPAR $y$ in the endothelium integrates metabolic and vascular phenotypes. Studies in mice lacking PPAR $y$ in the endothelium identify endothelial PPAR as controlling specific metabolic and vascular responses to high-fat diet, as summarized. After high-fat diet feeding, mice lacking endothelial PPAR $\gamma$ manifest increased plasma TG and FFA levels, decreased adiposity, less skeletal muscle TG accumulation, and decreased insulin resistance (IR). This phenotype derives from endothelial PPAR $\gamma$ regulation of target genes involved in TG metabolism as well as FA uptake and handling, including Cd36, aP2, CRBP-III, and Gpihbp1. In contrast, livers in endothelial PPAR $\gamma$-deficient mice have greater TG accumulation, increased VLDL production, and decreased AKT phosphorylation. In the liver, the endothelium is fenestrated, which fosters FFA uptake, while in skeletal muscle and adipose tissue, a nonfenestrated endothelium is found. The dyslipidemia seen in endothelial PPAR $\gamma$-deficient mice after high-fat diet and acute lipid loading involves both increased VLDL production and inhibition of LPL function by elevated FFA levels. The metabolic improvements evident in endothelial PPAR $\gamma$-deficient mice contrast with their impaired arterial vasodilation, highlighting the tissue-specific actions of endothelial PPAR $\gamma$, the role of the endothelium in directing metabolic responses, and the concept of metabolic endothelial function/dysfunction.

multilocular adipocytes in adipose tissue (19), although others have not found such effects (20). In the Tie2Cre model, neither the presence nor absence of PPAR $\gamma$ in BM $(\gamma E C-W T / B M-W T$ or $\gamma$ EC-WT/BM-KO mice, respectively; Figures 5 and 6 ) altered fat accumulation. The impact of hematopoietic PPAR $\gamma$ on adiposity requires further investigation.

More specifically, PPAR $\gamma$ deletion in macrophages has been reported to increase adiposity and promote insulin resistance in a high-fat diet-fed model $(56,57)$. We did not observe worsening insulin resistance despite Tie2-mediated PPAR $\gamma$ deletion in hematopoietic cells. Other studies reported that Tie2-mediated PPAR $\gamma$ deletion increased osteopetrosis and resulted in inflammatory maternal milk $(14,58)$. Strain differences may contribute to these variable findings, as suggested by recent work that also reported no effect of macrophage PPAR $\gamma$ on insulin sensitivity exists (59). Variations in the dietary stimulation used in these studies may also contribute to the differences seen. Of note, both $\gamma \mathrm{EC} / \mathrm{BM}$ $\mathrm{KO}$ and $\gamma \mathrm{EC} / \mathrm{BM}-\mathrm{WT}$ mice have predominant noninflammatory monocyte subsets (data not shown), a factor recently implicated in atherosclerosis (60), obesity (61), and insulin resistance (56). In terms of inflammation, we did not observe significant differences in TNF- $\alpha$ and IL-6 levels in adipose tissue (data not shown). The time course of macrophage infiltration into adipose tissue may also factor into the impact of hematopoietic PPAR $\gamma$ deletion on insulin resistance. Inflammatory macrophages are recruited to adipose tissue in later stages of obesity; our studies were done after approximately 12 weeks of high-fat diet, when macrophage infiltration is less obvious (62).

Taken together, we demonstrate here that endothelial PPAR $\gamma$ integrates both metabolic and vascular responses. In the presence of endothelial PPAR $\gamma$ deletion, FFA levels, TG-rich lipoprotein metabolism, adiposity, and insulin sensitivity in response to high-fat diet or an oral lipid challenge are altered. Prior studies in this same Tie2Cre model of PPAR $\gamma$ deletion have shown that high-fat diet induces hypertension (11). In that prior report and our studies here, changes through endothelial PPAR $\gamma$ were particularly evident in response to high-fat diet, emphasizing the importance of PPAR $\gamma$ in the handling of fat and FAs that are commonly encountered in Western diets. Although endothelial PPAR $\gamma$-deficient mice are protected against increased adiposity and insulin resistance, they still manifest abnormal vasodilatory responses, effectively disassociating the role of endothelial PPAR $\gamma$ in metabolism from its local effect on the arterial wall. In so doing, a more precise and expansive systemic role for the endothelium is evident. In humans, endothelial dysfunction occurs early in the natural history of obesity and diabetes, often preceding frank hyperglycemia $(2,3)$. Indeed, endothelial dysfunction can be found disproportionately among young, normotensive firstdegree relatives of those with diabetes (63). The evidence provided here implicating PPAR $\gamma$ in the endothelium in directing metabolic phenotype and therapeutic responses argues that our understanding of endothelial action may need to be extended to include concepts of metabolic endothelial function and dysfunction.

\section{Methods}

Mice. PPAR $\gamma$-floxed and Tie2Cre mice, as previously described, are of mixed C57BL6/N;Sv129;FVB/N background (11). Using sibling matings ( $\gamma \mathrm{EC} / \mathrm{BM}-\mathrm{KO}$ males and $\gamma \mathrm{EC} / \mathrm{BM}-\mathrm{WT}$ females), mice were bred for at least 12 generations before studies on male $\gamma \mathrm{EC} / \mathrm{BM}-\mathrm{KO}$ and $\gamma \mathrm{EC} / \mathrm{BM}$ WT mice. All mice were housed on a 12-hour light/dark cycle, with food and water ad libitum. Animal care and experimentation was approved by the Harvard Medical School Institutional Animal Care and Use Committee.

Before study, all mice were fed a standard pellet diet (13.2\% calories from fat; PicoLab Rodent 20 no. 5053, Lab Diet Inc.). Obesity was induced using a high-fat diet (60\% calories from fat; D12492, Research Diets Inc.) for 12-27 weeks, beginning at 6 weeks of age. Low-fat diet-fed mice received the standard pellet diet throughout life. For rosiglitazone experiments, mice were fed standard diet (AIN-76A Rodent Diet, Research Diets Inc.), with or without $130 \mathrm{mg}$ rosiglitazone $/ \mathrm{kg}$ diet (ad libitum, 5 weeks; GlaxoSmithKline). The rosiglitazone dose was determined by pilot dose ranging studies. For olive oil gavage experiments with rosiglitazone, mice were fed the AIN-76A diet, with or without $70 \mathrm{mg}$ rosiglitazone/kg diet (ad libitum, 3 weeks).

Mouse EC isolation. Microvascular ECs were isolated from mouse hearts (at 1 month of age), using ICAM-2 and PECAM-1 antibody (BD Biosciences - Pharmingen) Dynabead selection as described before (64).

RNA analysis. DNase I-treated total RNA was reverse transcribed, and real-time quantitative PCR with cDNA was performed using SYBR Green I (iCycler iQ Real-Time PCR Detection System; Bio-Rad). Sense and antisense cDNA primers, respectively, were as follows: Pparg, 5' -CAAGAATACCAAAGTGCGATCAA-3' ' 5'-GAGCAGGGTCTTTTCAGAATAATAAG-3'; Cd36, 5'-GGCCAAGCTATTGCGACAT-3', 5'-CAGATCCGAACACAGCG- 
TAGA-3'; Lpl, 5'-GTGGCCGAGAGCGAGAAC-3', 5'-AAGAAGGAGTAGGTTTTATTTGTGGAA-3'; Lipg, 5'-ATGCGAAACACGGTTTTCCTG-3', 5'-GTAGCTGGTACTCCAGTGGG-3'; aP2, 5'-TGGAAGCTTGTCTCCAGTGA-3', 5'-AATCCCCATTTACGCTGATG-3'; Gpihbp 1, 5'-TCTTGCTACTAAGTGGACAGCCAG-3', 5'-TGCTTCCAGGGATCATGTTGGTCT-3'; Pparg2, 5'-AACTCTGGGAGATTCTCCTGTTGA-3', 5'-TGGTAATTTCTTGTGAAGTGCTCATA-3'; CRBP-III, 5'-AAATGCACGAGCCTGGTTAC-3', 5'-CAGGCTCTCTGGAAGGTTTG-3'; Actb, 5'-CAGCCTTCCTTCTTGGGTATGG-3', 5'-CTGTGTTGGCATAGAGGTCTTTACG-3'; 36B4, 5'-GGCCCTGCACTCTCGCTTTC-3', 5'-TGCCAGGACGCGCTTGT-3'. mRNA levels of these genes were quantified and expressed normalized to $\beta$-actin or $36 \mathrm{~B} 4$ as an internal control.

In vivo insulin signaling studies. Mice were fasted overnight (17 hours) before tail vein injection with human insulin (10 U/kg body weight) or saline. Five minutes after injection, skeletal muscle (hind limb) and liver were dissected and snap frozen in liquid nitrogen for immunoblotting (65).

Western blotting. After lysis in solubilization buffer, immunoblotting was performed as described before, using specific antibodies against AKT, phospho-AKT(Ser ${ }^{473}$ ) (both from Cell Signaling Technology), CD36, and GAPDH (both from Santa Cruz Biotechnology Inc.) (66) before densitometric analysis (ImageJ software; http://rsbweb.nih.gov/ij/).

Histological analysis. Paraffin-embedded adipose tissue was analyzed by H\&E staining, before area measurement (ImageJ software; http://rsbweb. nih.gov/ij/) in more than 5 representative images and 300 cells per mouse.

Metabolic testing. Glucose tolerance tests were performed after an overnight fasting. Blood glucose concentrations were measured before and $15,30,60,120$, and 180 minutes after an intraperitoneal glucose injection $(1 \mathrm{~g} / \mathrm{kg}$; Freestyle Glucose Monitoring System, Abbott Laboratories). Insulin tolerance testing was carried out in animals fasted for 6 hours, beginning at approximately $9 \mathrm{AM}$. After recombinant human regular insulin intraperitoneal bolus injection ( $0.75 \mathrm{U} / \mathrm{kg}$; Novolin R, Novo Nordisk Inc.), blood glucose concentrations were measured before and 15, 30, 60, and 120 minutes after injection.

Serum metabolites. Overnight fasted blood samples were placed at room temperature (30 minutes) before cooling on ice and centrifugation $(700 \mathrm{~g}$, 15 minutes, $4^{\circ} \mathrm{C}$ ). Serum FFA and TG levels were determined by kits (L-Type TG Kit and NEFA-HR Kit; Wako Chemicals). Serum adiponectin and resistin were determined by ELISA (Quantikine Mouse; R\&D Systems). Kits were used to assay serum leptin (fed state), insulin (Mouse Leptin ELISA Kit and Ultra Sensitive Insulin ELISA Kit; Crystal Chem Inc.), and retinol binding protein 4 (Retinol Binding Protein 4 EIA; ALPCO Diagnostics).

Tissue lipid content. Lipid extraction was performed using the Bligh-Dyer method (67). Skeletal and liver tissues were homogenized in chloroform/ $\mathrm{MeOH} / \mathrm{H}_{2} \mathrm{O}$ (1:2:0.8; room temperature) before centrifugation, and supernatants were removed to equal amounts of chloroform $/ \mathrm{H}_{2} \mathrm{O}$. After vortexing and centrifugation, the chloroform layer was obtained, completely dried, and resuspended ( $90 \%$ isopropanol, $10 \%$ Triton X-100), before TG concentration measurement (L-Type TG Kit; Wako Chemicals).

$B M T$. Eight-week-old recipient mice were lethally irradiated (10 Gy). Untransplanted mice died within 2 weeks of irradiation. BM cells from both femurs and tibias were collected in sterile conditions. Approximately $5 \times 10^{5}$ unfractionated nucleated cells per recipient mouse were delivered intravenously into tail veins. Two months after transplantation, splenic lymphocytes were evaluated for engraftment by real-time quantitative PCR. Mice were placed on a high-fat diet for 20 weeks, 4 weeks after BMT.

Lipoprotein profiling. Eight- to sixteen-week-old age-matched mice were used for measuring FFAs and TGs. Mice that consumed standard chow were deprived of food for 24 hours, starting at the beginning of the light cycle. Before and 24 hours after starvation, blood samples were taken. Mice consuming standard chow were fasted overnight before olive oil gavage
(10 ml/kg; Sigma-Aldrich), followed by serum FFA and TG level assays in tail vein blood. Plasma lipoproteins were analyzed by HPLC, using molecular sieve columns (Skylight Biotech). Lipoprotein subclasses were defined based on lipoprotein particle size (diameter) (68).

FA uptake. Primary mouse heart ECs were treated for 24 hours with or without rosiglitazone $(1 \mu \mathrm{M})$ before serum deprivation (for 2 hours). Uptake of a fluorescently labeled long-chain FA (BODIPY-dodecanoic acid) was measured 10 minutes after adding QBT FA Uptake solution (Molecular Devices). Plates were read in the SpectraMax M2e microplate reader (excitation, $485 \mathrm{~nm}$; emission, $515 \mathrm{~nm}$; cutoff, $495 \mathrm{~nm}$; Molecular Devices).

Hepatic VLDL production. After 24 hours without food, mice were injected intravenously into the tail vein with Triton WR1339 $(500 \mathrm{mg} / \mathrm{kg}$ body weight, $10 \%$ solution, $0.9 \% \mathrm{NaCl}$ ), which inhibits lipoprotein clearance (33). Blood was sampled before (0 hours) and after (1 and 2 hours) injection. TG was measured enzymatically as above. VLDL production rate ( $\mathrm{mg} / \mathrm{kg} /$ hour) was calculated, assuming plasma volume to be $3.5 \%$ body weight and subtracting the baseline value from the 2-hour value, and then expressed per hour as previously reported (69).

Determination of LPL and HL activity in post-heparin plasma. Two and a half hours after olive oil administration, mice were injected intraperitoneally with sodium heparin (200 U) (70). Thirty minutes later, venipuncture was performed, plasma was isolated and snap frozen, and lipase activity was assayed using differential salt concentrations as reported $(22,71,72)$. Briefly, a glycerol-stabilized emulsion of triolein and egg phosphatidylcholine containing glycerol-tri[ $[9,10(\mathrm{n})-3 \mathrm{H}]$ oleate was used. Before incubation (1 hour, $37^{\circ} \mathrm{C}$ ), $0.05 \mathrm{M}$ Tris- $\mathrm{HCl}$, $\mathrm{pH}$ 8.0, 0.75\% BSA, $3.4 \mathrm{mM}$ triolein, 250 $\mu \mathrm{M}$ phosphatidylcholine, and $\mathrm{NaCl}$ at either $0.15 \mathrm{M}$ (LPL) or $1 \mathrm{M}(\mathrm{HL})$ was combined with mouse plasma in a total volume of $0.3 \mathrm{ml}$. Liberated FAs were quantified by scintillation counting ( $0.5 \mathrm{ml}$ aliquot, aqueous phase). Under these conditions, the partition coefficient of oleic acid was approximately 0.4. FFA effects on LPL and HL activity in post-heparin plasma was determined by incubation with emulsion particles in the absence or presence of excess FFA-free BSA (Sigma-Aldrich) as a FFA reservoir.

Vascular reactivity studies. After sacrifice (pentobarbital), left carotid arteries were removed and mounted onto glass cannulae in a pressure myograph (Living Systems) and maintained with perfusion $(80 \mathrm{mmHg}$ pressure, $37^{\circ} \mathrm{C}$ ) in physiologic saline solution (PSS), containing $130 \mathrm{mM}$ $\mathrm{NaCl}, 4.7 \mathrm{mM} \mathrm{KCl}, 1.17 \mathrm{mM} \mathrm{MgSO}_{4}, 14.9 \mathrm{mM} \mathrm{NaHCO}_{3}, 1.6 \mathrm{mM} \mathrm{CaCl}_{2}$, $1.18 \mathrm{mM} \mathrm{KH}_{2} \mathrm{PO}_{4}, 0.026 \mathrm{mM}$ EDTA, and $5.5 \mathrm{mM}$ glucose. Continuous buffer aeration $\left(95 \% \mathrm{O}_{2}, 5 \% \mathrm{CO}_{2}\right)$ maintained $\mathrm{pH}$ 7.2-7.4. Vessel diameter was continuously recorded by video (IonWizard 4.4; IonOptix Corp.). Vessels were equilibrated in PSS alone for 60 minutes before phenylephrine constriction (10-5 M, 60 minutes). Vessel relaxation dose-response curves were generated using increasing carbachol concentrations $\left(10^{-8}-10^{-5} \mathrm{M}\right)$ added to the organ bath, expressing relaxation as the percentage change in diameter after phenylephrine preconstriction compared with the diameter before phenylephrine constriction, using the following equation: percentage dilation $=100 \% \times\left[\left(D_{x}-D_{i}\right) /\left(B-D_{i}\right)\right]$, where $D$ is the measured arterial diameter, subscripts $x$ and $i$ denote arterial diameters at each dose of agonist $(x)$ and initial diameter following phenylephrine constriction (i), and $B$ is the basal arterial diameter before phenylephrine constriction. For each experiment, carotid arteries from WT and KO mice were studied simultaneously in a 2-vessel myograph. Experiments were repeated at least 4 times in independent preparations.

Statistics. Data are expressed as mean \pm SEM. Data were analyzed by unpaired 2-tailed Student's $t$ test, 1- or 2-way ANOVA as appropriate. Comparisons between time points were analyzed using repeated-measures ANOVA. Correlation coefficients $(r)$ were determined using the Pearson product-moment method. $P$ values of less than 0.05 were considered statistically significant. 


\section{Acknowledgments}

This work was supported by the Sankyo Foundation of Life Science, the Mochida Memorial Foundation for Medical and Pharmaceutical Research, and the Uehara Memorial Foundation (to T. Kanda) and by the NIH National Heart Lung and Blood Institute grants R01 HL071745 (to J. Plutzky) and P01 HL48743 (to T. Michel and J. Plutzky).
Received for publication May 19, 2008, and accepted in revised form November 5, 2008.

Address correspondence to: Jorge Plutzky, Brigham and Women's Hospital, New Research Building, 77 Avenue Louis Pasteur, NRB 742, Boston, Massachusetts 02115, USA. Phone: (617) 525-4360; Fax: (617) 525-4366; E-mail: jplutzky@rics.bwh.harvard.edu.
1. Cleaver, O., and Melton, D.A. 2003. Endothelial signaling during development. Nat. Med. 9:661-668.

2. Steinberg, H.O., et al. 1996. Obesity/insulin resistance is associated with endothelial dysfunction. Implications for the syndrome of insulin resistance. J. Clin. Invest. 97:2601-2610.

3. Meigs, J.B., Hu, F.B., Rifai, N., and Manson, J.E. 2004. Biomarkers of endothelial dysfunction and risk of type 2 diabetes mellitus. JAMA. 291:1978-1986.

4. Tontonoz, P., Hu, E., Graves, R.A., Budavari, A.I., and Spiegelman, B.M. 1994. mPPAR gamma 2: tissue-specific regulator of an adipocyte enhancer. Genes Dev. 8:1224-1234.

5. Chawla, A., Schwarz, E.J., Dimaculangan, D.D., and Lazar, M.A. 1994. Peroxisome proliferator-activated receptor (PPAR) gamma: adipose-predominant expression and induction early in adipocyte differentiation. Endocrinology. 135:798-800.

6. Lehrke, M., and Lazar, M.A. 2005. The many faces of PPARgamma. Cell. 123:993-999.

7. Marx, N., Bourcier, T., Sukhova, G.K., Libby, P., and Plutzky, J. 1999. PPARgamma activation in human endothelial cells increases plasminogen activator inhibitor type-1 expression: PPARgamma as a potential mediator in vascular disease. Arterioscler. Thromb. Vasc. Biol. 19:546-551.

8. Delerive, P., et al. 1999. Peroxisome proliferatoractivated receptor activators inhibit thrombininduced endothelin-1 production in human vascular endothelial cells by inhibiting the activator protein-1 signaling pathway. Circ. Res. 85:394-402.

9. Xin, X., Yang, S., Kowalski, J., and Gerritsen, M.E. 1999. Peroxisome proliferator-activated receptor gamma ligands are potent inhibitors of angiogenesis in vitro and in vivo. J. Biol. Chem. 274:9116-9121.

10. Brown, J.D., and Plutzky, J. 2007. Peroxisome proliferator-activated receptors as transcriptional nodal points and therapeutic targets. Circulation. 115:518-533.

11. Nicol, C.J., Adachi, M., Akiyama, T.E., and Gonzalez, F.J. 2005. PPARgamma in endothelial cells influences high fat diet-induced hypertension. Am. J. Hypertens. 18:549-556.

12. Wang, L., Fuster, M., Sriramarao, P., and Esko, J.D. 2005. Endothelial heparan sulfate deficiency impairs L-selectin- and chemokine-mediated neutrophil trafficking during inflammatory responses. Nat. Immunol. 6:902-910.

13. Kisanuki, Y.Y., et al. 2001. Tie2-Cre transgenic mice: a new model for endothelial cell-lineage analysis in vivo. Dev. Biol. 230:230-242.

14. Wan, Y., Chong, L.W., and Evans, R.M. 2007. PPARgamma regulates osteoclastogenesis in mice. Nat. Med. 13:1496-1503.

15. Katagiri, H., Yamada, T., and Oka, Y. 2007. Adiposity and cardiovascular disorders: disturbance of the regulatory system consisting of humoral and neuronal signals. Circ. Res. 101:27-39.

16. McGarry, J.D. 2002. Banting lecture 2001: dysregulation of fatty acid metabolism in the etiology of type 2 diabetes. Diabetes. 51:7-18.

17. Pan, D.A., et al. 1997. Skeletal muscle triglyceride levels are inversely related to insulin action. Diabetes. 46:983-988.

18. Festuccia, W.T., Laplante, M., Berthiaume, M., Gelinas, Y., and Deshaies, Y. 2006. PPARgamma agonism increases rat adipose tissue lipolysis, expression of glyceride lipases, and the response of lipolysis to hormonal control. Diabetologia. 49:2427-2436.

19. Crossno, J.T., Jr., et al. 2006. Rosiglitazone promotes development of a novel adipocyte population from bone marrow-derived circulating progenitor cells. J. Clin. Invest. 116:3220-3228.

20. Koh, Y.J., et al. 2007. Bone marrow-derived circulating progenitor cells fail to transdifferentiate into adipocytes in adult adipose tissues in mice. J. Clin. Invest. 117:3684-3695.

21. Drover, V.A., et al. 2005. CD36 deficiency impairs intestinal lipid secretion and clearance of chylomicrons from the blood. J. Clin. Invest. 115:1290-1297.

22. Goudriaan, J.R., et al. 2005. CD36 deficiency in mice impairs lipoprotein lipase-mediated triglyceride clearance. J. Lipid Res. 46:2175-2181.

23. Hajri, T., and Abumrad, N.A. 2002. Fatty acid transport across membranes: relevance to nutrition and metabolic pathology. Annu. Rev. Nutr. 22:383-415.

24. Hajri, T., Han, X.X., Bonen, A., and Abumrad, N.A. 2002. Defective fatty acid uptake modulates insulin responsiveness and metabolic responses to diet in CD36-null mice. J. Clin. Invest. 109:1381-1389.

25. Hajri, T., et al. 2007. CD36-facilitated fatty acid uptake inhibits leptin production and signaling in adipose tissue. Diabetes. 56:1872-1880.

26. Beigneux, A.P., et al. 2007. Glycosylphosphatidylinositol-anchored high-density lipoproteinbinding protein 1 plays a critical role in the lipolytic processing of chylomicrons. Cell Metab. 5:279-291.

27. Davies, B.S., et al. 2008. The expression of GHIBP1, an endothelial cell binding site for lipoprotein lipase and chylomicrons, is induced by peroxisome proliferator-activated receptor-gamma. Mol. Endocrinol. 22:2496-2504.

28. Caprioli, A., Zhu, H., and Sato, T.N. 2004. CRBP-III: lacZ expression pattern reveals a novel heterogeneity of vascular endothelial cells. Genesis. 40:139-145.

29. Vogel, S., et al. 2001. Characterization of a new member of the fatty acid-binding protein family that binds all-trans-retinol. J. Biol. Chem. 276:1353-1360.

30. Zizola, C.F., Schwartz, G.J., and Vogel, S. 2008. Cellular retinol-binding protein, type III (CRBP-III) is a PPAR-gamma target gene and plays a role in lipid metabolism. Am. J. Physiol. Endocrinol. Metab. Online publication ahead of print. doi:10.1152/ ajpendo.90464.2008.

31. Lewis, G.F., Uffelman, K.D., Szeto, L.W., Weller, B., and Steiner, G. 1995. Interaction between free fatty acids and insulin in the acute control of very low density lipoprotein production in humans. J. Clin. Invest. 95:158-166.

32. Peterson, J., et al. 1990. Fatty acid control of lipoprotein lipase: a link between energy metabolism and lipid transport. Proc. Natl. Acad. Sci. U. S. A. 87:909-913.

33. Aalto-Setala, K., et al. 1992. Mechanism of hypertriglyceridemia in human apolipoprotein (apo) CIII transgenic mice. Diminished very low density lipoprotein fractional catabolic rate associated with increased apo CIII and reduced apo E on the particles. J. Clin. Invest. 90:1889-1900.

34. Beyer, A.M., et al. 2008. Endothelium-specific interference with peroxisome proliferator activated receptor gamma causes cerebral vascular dysfunction in response to a high-fat diet. Circ. Res. 103:654-661.

35. Van Gaal, L.F., Mertens, I.L., and De Block, C.E. 2006. Mechanisms linking obesity with cardiovas- cular disease. Nature. 444:875-880.

36. Smith, S.R., et al. 2005. Effect of pioglitazone on body composition and energy expenditure: a randomized controlled trial. Metabolism. 54:24-32.

37. Miyazaki, Y., et al. 2002. Effect of pioglitazone on abdominal fat distribution and insulin sensitivity in type 2 diabetic patients. J. Clin. Endocrinol. Metab. 87:2784-2791.

38. Tan, G.D., et al. 2005. The effects of rosiglitazone on fatty acid and triglyceride metabolism in type 2 diabetes. Diabetologia. 48:83-95.

39. Scow, R.O., Blanchette-Mackie, E.J., and Smith, L.C. 1976. Role of capillary endothelium in the clearance of chylomicrons. A model for lipid transport from blood by lateral diffusion in cell membranes. Circ. Res. 39:149-162.

40. van der Vusse, G.J., et al. 2002. Critical steps in cellular fatty acid uptake and utilization. Mol. Cell. Biochem. 239:9-15.

41. Bassingthwaighte, J.B., Noodleman, L., van der Vusse, G., and Glatz, J.F. 1989. Modeling of palmitate transport in the heart. Mol. Cell. Biochem. 88:51-58.

42. Van der Vusse, G.J., et al. 1998. Transport of longchain fatty acids across the muscular endothelium. Adv. Exp. Med. Biol. 441:181-191.

43. Koonen, D.P., et al. 2007. Increased hepatic CD36 expression contributes to dyslipidemia associated with diet-induced obesity. Diabetes. 56:2863-2871.

44. Tamura, S., and Shimomura, I. 2005. Contribution of adipose tissue and de novo lipogenesis to nonalcoholic fatty liver disease. J. Clin. Invest. 115:1139-1142.

45. Lessard, S.J., et al. 2007. Tissue-specific effects of rosiglitazone and exercise in the treatment of lipidinduced insulin resistance. Diabetes. 56:1856-1864.

46. Oakes, N.D., Thalen, P.G., Jacinto, S.M., and Ljung, B. 2001. Thiazolidinediones increase plasma-adipose tissue FFA exchange capacity and enhance insulin-mediated control of systemic FFA availability. Diabetes. 50:1158-1165.

47. Kubota, N., et al. 1999. PPAR gamma mediates high-fat diet-induced adipocyte hypertrophy and insulin resistance. Mol. Cell. 4:597-609.

48. Yamauchi, T., et al. 2001. The mechanisms by which both heterozygous peroxisome proliferator-activated receptor gamma (PPARgamma) deficiency and PPARgamma agonist improve insulin resistance. J. Biol. Chem. 276:41245-41254.

49. Seda, O., Kazdova, L., Krenova, D., and Kren, V. 2003. Rosiglitazone fails to improve hypertriglyceridemia and glucose tolerance in CD36-deficient BN.SHR4 congenic rat strain. Physiol. Genomics. 12:73-78.

50. Adams, M., et al. 1997. Activators of peroxisome proliferator-activated receptor gamma have depotspecific effects on human preadipocyte differentiation. J. Clin. Invest. 100:3149-3153.

51. Laplante, M., et al. 2006. Mechanisms of the depot specificity of peroxisome proliferator-activated receptor gamma action on adipose tissue metabolism. Diabetes. 55:2771-2778.

52. Qi, N., et al. 2002. Pharmacogenetic evidence that cd36 is a key determinant of the metabolic effects of pioglitazone. J. Biol. Chem. 277:48501-48507.

53. Perseghin, G., Ghosh, S., Gerow, K., and Shulman, G.I. 1997. Metabolic defects in lean nondiabetic offspring of NIDDM parents: a cross-sectional study. Diabetes. 46:1001-1009. 
54. Schenk, S., Saberi, M., and Olefsky, J.M. 2008. Insulin sensitivity: modulation by nutrients and inflammation. J. Clin. Invest. 118:2992-3002.

55. Shi, H., et al. 2006. TLR4 links innate immunity and fatty acid-induced insulin resistance. J. Clin. Invest. 116:3015-3025.

56. Odegaard, J.I., et al. 2007. Macrophage-specific PPARgamma controls alternative activation and improves insulin resistance. Nature. 447:1116-1120.

57. Hevener, A.L., et al. 2007. Macrophage PPAR gamma is required for normal skeletal muscle and hepatic insulin sensitivity and full antidiabetic effects of thiazolidinediones. J. Clin. Invest. 117:1658-1669.

58. Wan, Y., et al. 2007. Maternal PPAR gamma protects nursing neonates by suppressing the production of inflammatory milk. Genes Dev. 21:1895-1908.

59. Marathe, C., et al. 2008. Preserved glucose tolerance in high-fat diet-fed C57BL/6 mice transplanted with PPARgamma -/-, PPARdelta -/-, PPARgamma delta -/- or LXRalpha beta -/- bone marrow. J. Lipid Res. Online publication ahead of print. doi:10.1194/jlr.M800189-JLR200.

60. Swirski, F.K., et al. 2007. Ly-6Chi monocytes domi- nate hypercholesterolemia-associated monocytosis and give rise to macrophages in atheromata. J. Clin. Invest. 117:195-205

61. Lumeng, C.N., Bodzin, J.L., and Saltiel, A.R. 2007. Obesity induces a phenotypic switch in adipose tissue macrophage polarization. J. Clin. Invest. 117:175-184.

62. Xu, H., et al. 2003. Chronic inflammation in fat plays a crucial role in the development of obesity-related insulin resistance. J. Clin. Invest. 112:1821-1830.

63. Balletshofer, B.M., et al. 2000. Endothelial dysfunction is detectable in young normotensive firstdegree relatives of subjects with type 2 diabetes in association with insulin resistance. Circulation. 101:1780-1784.

64. Lim, Y.C., et al. 2003. Heterogeneity of endothelial cells from different organ sites in T-cell subset recruitment. Am. J. Pathol. 162:1591-1601.

65. Uno, K., et al. 2006. Neuronal pathway from the liver modulates energy expenditure and systemic insulin sensitivity. Science. 312:1656-1659.

66. Ziouzenkova, O., et al. 2003. Dual roles for lipolysis and oxidation in peroxisome proliferation-activa- tor receptor responses to electronegative low density lipoprotein. J. Biol. Chem. 278:39874-39881.

67. Bligh, E.G., and Dyer, W.J. 1959. A rapid method of total lipid extraction and purification. Can. J. Biochem. Physiol. 37:911-917.

68. Okazaki, M., et al. 2005. Identification of unique lipoprotein subclasses for visceral obesity by component analysis of cholesterol profile in highperformance liquid chromatography. Arterioscler. Thromb. Vasc. Biol. 25:578-584.

69. Millar, J.S., et al. 2006. Short-term overexpression of DGAT1 or DGAT2 increases hepatic triglyceride but not VLDL triglyceride or apoB production. J. Lipid Res. 47:2297-2305.

70. Tordjman, K., et al. 2001. PPARalpha deficiency reduces insulin resistance and atherosclerosis in apoE-null mice. J. Clin. Invest. 107:1025-1034.

71. McCoy, M.G., et al. 2002. Characterization of the lipolytic activity of endothelial lipase. J. Lipid Res. 43:921-929.

72. Nilsson-Ehle, P., and Schotz, M.C. 1976. A stable, radioactive substrate emulsion for assay of lipoprotein lipase. J. Lipid Res. 17:536-541. 